\title{
Modeling the nitrogen fluxes in the Black Sea using a 3D coupled hydrodynamical-biogeochemical model: transport versus biogeochemical processes, exchanges across the shelf break and comparison of the shelf and deep sea ecodynamics
}

\author{
M. Grégoire ${ }^{1,2}$ and J. M. Beckers ${ }^{1}$ \\ ${ }^{1}$ University of Liège, 1 Mare, B6c, Sart-Tilman, 4000 Liège, Belgium \\ ${ }^{2}$ Netherlands Institute of Ecology (NIOO - KNAW), Centre for Estuarine and Marine Ecology, Korringaweg 7, 4401 NT \\ Yerseke, The Netherlands
}

Received: 28 May 2004 - Published in Biogeosciences Discussions: 21 June 2004

Revised: 14 September 2004 - Accepted: 15 September 2004 - Published: 5 October 2004

\begin{abstract}
A 6-compartment biogeochemical model of nitrogen cycling and plankton productivity has been coupled with a 3D general circulation model in an enclosed environment (the Black Sea) so as to quantify and compare, on a seasonal and annual scale, the typical internal biogeochemical functioning of the shelf and of the deep sea as well as to estimate the nitrogen and water exchanges at the shelf break. Model results indicate that the annual nitrogen net export to the deep sea roughly corresponds to the annual load of nitrogen discharged by the rivers on the shelf.

The model estimated vertically integrated gross annual primary production is $130 \mathrm{~g} \mathrm{C} \mathrm{m}^{-2} \mathrm{yr}^{-1}$ for the whole basin, $220 \mathrm{~g} \mathrm{C} \mathrm{m}^{-2} \mathrm{yr}^{-1}$ for the shelf and $40 \mathrm{~g} \mathrm{C} \mathrm{m}^{-2} \mathrm{yr}^{-1}$ for the central basin. In agreement with sediment trap observations, model results indicate a rapid and efficient recycling of particulate organic matter in the sub-oxic portion of the water column $(60-80 \mathrm{~m})$ of the open sea. More than $95 \%$ of the PON produced in the euphotic layer is recycled in the upper $100 \mathrm{~m}$ of the water column, $87 \%$ in the upper $80 \mathrm{~m}$ and $67 \%$ in the euphotic layer. The model estimates the annual export of POC towards the anoxic layer to $410^{10} \mathrm{~mol} \mathrm{yr}^{-1}$. This POC is definitely lost for the system and represents $2 \%$ of the annual primary production of the open sea.
\end{abstract}

\section{Introduction}

Recent decades have seen a degradation of the environmental quality in various basins of the world's oceans caused by eutrophication and pollution problems resulting from increased anthropogenic inputs of terrestrial origin (e.g. min-

Correspondence to: M. Grégoire

(m.gregoire@nioo.knaw.nl) eralized nutrients, organic and inorganic pollutants). Such problems affect particularly the coastal zone located at the interface between the continent and the ocean and thus exposed to increasing socio-economic pressures at sea and from the drainage basin network and may lead to dramatic alterations of the structure and functioning of the ecosystem with an amplitude depending on the ability of the ecosystem to be able to adapt to new circumstances. In particular, as a result of their small inertia related to their geometry, the various semienclosed seas and enclosed inland bodies are the regions the most sensitive to natural and anthropogenic perturbations of their environment.

Because the eutrophication-induced biological production has severe consequences for local tourism, fishery and economy, ecosystem modeling studies devoted to coastal regions and shelf seas have received a particularly great interest (e.g. Dippner, 1993; Yanagi et al., 1995; Patsch and Radach, 1997; Tagushi and Nakata, 1998; Lancelot et al., 2002). Indeed, ecosystem models are necessary to assess the ecosystem's vulnerability to contaminants of anthropogenic origin and to calculate the transfer and accumulation of toxic substances from one level of the foodweb to the next. Furthermore, one realizes that the study of the eutrophication problems and their impacts on the basin scale ecosystem cannot be made without considering the physical processes leading to the mixing and transport of pollutants and biogeochemical constituents discharged by the rivers. For this reason, box models are more and more replaced by time-dependent three-dimensional active transport-dispersion models, with multiple interactions between the state variables, for predicting coupled physical-biogeochemical dynamical processes in marine ecosystems of various regions of the world's oceans (e.g. Sarmiento et al., 1993; McGillicuddy et al., 1995; 
Delhez, 1996; Grégoire and Lacroix, 2001; Grégoire et al.,2004). Such models are absolutely needed if one wants to quantify the nutrient and water exchanges between the shelf and the deep sea at the shelf break. Such a model is presented here and is applied in the Black Sea.

The Black Sea is by large an elliptical basin with an area of $423000 \mathrm{~km}^{2}$ and a volume of $534000 \mathrm{~km}^{3}$ which has only restricted exchanges with the Mediterranean Sea through the narrow Bosphorus strait (Fig. 1). This marine area exhibits topographic and hydrographic specificities which make it interesting for testing models and processes. It presents a large variety of topography with a flat abyssal plain (maximum depth $2200 \mathrm{~m}$ ) in the central part and an almost $200 \mathrm{~km}$ wide shelf in the north-western area (depth $<100 \mathrm{~m}$, constituting $25 \%$ of the total area). The northwestern shelf forms a shallow receptacle for the most important Black Sea rivers (i.e. the Danube, the Dnestr and the Dnepr), and is well known to be a region of enhanced biological production fed by the nutrients brought by the river discharges, as shown by satellite images (e.g. Sur et al., 1994; Nezlin et al., 1999). The landlocked geometry of the Black Sea basin makes easier the computation of water and nitrogen budgets to check the internal consistency of the model dynamics and the convergence towards a steady state solution.

The Black Sea is a typical example of estuarine basin and therefore, its overall mass budget and hydrochemical structure critically depend on elements of the hydrological balance. Its hydrographic regime is characterized by low salinity surface waters of river origin overlying high-salinity deep waters of Mediterranean origin. As a result, a permanent pycnocline (or more precisely a halocline) develops with a depth varying horizontally according to the local hydrodynamics between $100-150 \mathrm{~m}$ and inhibits the exchanges between the surface and deep waters. These conditions have made the Black Sea almost completely anoxic with oxygen only in the upper $150 \mathrm{~m}$ depth (13\% of the sea volume) and hydrogen sulfide and methane in the deep waters. The atmospheric forcings only affect the surface layer and cold intermediate waters and, therefore, waters below $500 \mathrm{~m}$ depth are essentially stagnant. The residence time increases from a few years for the layer of the main pycnocline (e.g. Unluata et al., 1990; Buesseler et al., 1991) to a few thousands of years for the deepest layer (e.g. Ozsoy and Unluata, 1997).

The above specific features give enough arguments to consider the Black Sea as a natural test area for modeling studies where the different factors leading to the degradation of its ecosystem can be identified and analyzed. Most of the mathematical models applied to the Black Sea to study the functioning of its ecosystem are limited to interaction box models (e.g. Cokacar and Ozsoy, 1998; Ozsoy et al., 1998) or to one-dimensional (vertical) coupled physical biogeochemical models usually describing the nitrogen cycling (e.g. Lebedeva and Shushkina, 1994; Oguz et al., 1996, 1999; Staneva et al., 1998; Lancelot et al., 2002). Models applied in the suboxic zone and describing the nitrogen and sulfur cycles coupled with oxygen dynamics (e.g. Yakushev and Neretin, 1997; Oguz et al., 1998) and also, to the manganese cycle (e.g. Yakushev, 1998; Oguz et al., 2000) have also been developed.

The model presented in this paper is used with the aim of understanding the macroscale (i.e. time scales of a few weeks to months) Black Sea's ecohydrodynamics and more specifically: (1) to estimate the transport at the shelf break of water, biogenic nutrients and plankton (2) to understand, quantify and compare the nitrogen cycling of the north-western shelf and of the deep sea, (3) to quantify the vertical flux of nitrate and PON at different depths of the central basin as well as its seasonal variability, (4) to estimate the free nitrogen production due to the denitrification process occurring in oxygendeficient waters and (5) to quantify the role of the Black Sea basin in the carbon exportation and sequestration (the efficiency of the biological pump) in the deep layers.

The paper is organized as follows. Section 2 briefly describes the coupled model and its convergence towards a steady state solution as well as the numerical scheme used to discretize the evolution equations of the biogeochemical components. Model results are described in Sect. 3. First, the main characteristics of the Black Sea's macroscale ecohydrodynamics simulated by the model are illustrated. Then, the seasonal variability of the water and nutrients transports at the shelf break is analyzed and the nitrogen budgets of the whole basin, the north-western shelf and the central basin are quantified. Finally, a discussion and conclusions are presented in Sect. 4.

\section{The mathematical tool: description of the three- dimensional model}

The three-dimensional model results from the on-line coupling between a general circulation model and an ecosystem model. The coupling is one way. Only the influence of the physics on the biology is taken into account.

\subsection{The hydrodynamical model}

The macroscale hydrodynamics of the Black Sea has been numerically simulated with the GHER general circulation model covering the whole basin $\left(27.15^{\circ} \mathrm{E}-\right.$ $\left.42.64^{\circ} \mathrm{E} \times 40.61^{\circ} \mathrm{N}-46.68^{\circ} \mathrm{N}\right)$. The GHER primitive equation model is derived from the general "marine weather" model by averaging over a time scale of several weeks. This model is three-dimensional, non linear, baroclinic and solves for the free surface, the three components of the current field, temperature, salinity and turbulent kinetic energy. Being an estuarine basin, the Black sea is very sensitive to variations in the fresh water balance. The resulting free surface movements are of utmost importance for establishing the circulation, and therefore the use of a free surface model allows to more adequately describe the variations of the sea surface 


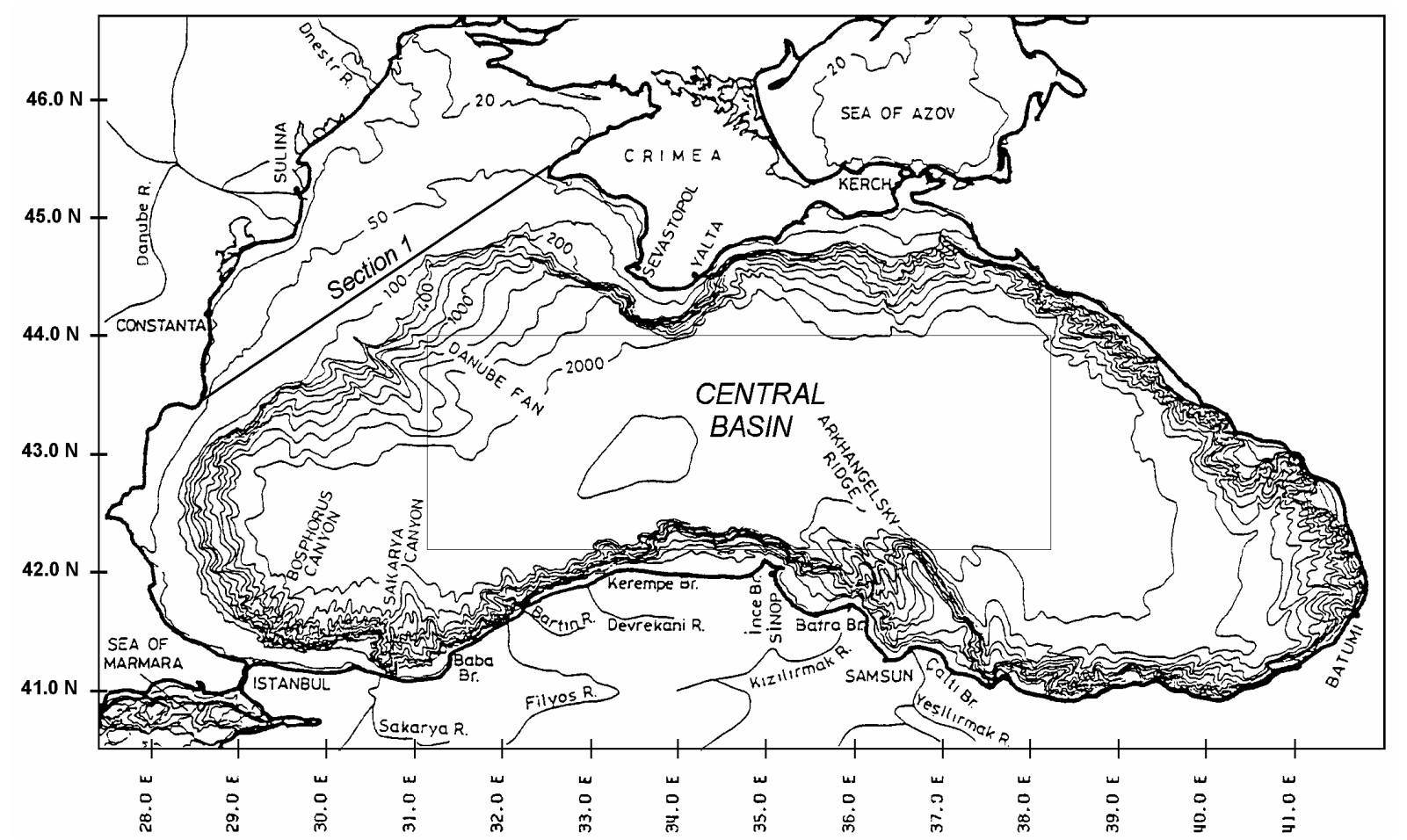

Fig. 1. Layout and bathymetry of the Black Sea basin. Depth contours are labelled in meters. (Figure reproduced from Ozsoy and Unluata, 1997). In our calculations of the nitrogen budget of the shelf and of the central basin, Sect. 1 (first point: $28.8^{\circ} \mathrm{E}, 43.45^{\circ} \mathrm{N}$; last point: $32.45^{\circ} \mathrm{E}, 45.4^{\circ} \mathrm{N}$ ) is assumed to represent the margin separating the north-western shelf and the deep sea, while the central basin is represented by the box covering $31.2^{\circ} \mathrm{E}-38.21^{\circ} \mathrm{E} \times 42.1^{\circ} \mathrm{N}-44^{\circ} \mathrm{N}$ and extending vertically to $55 \mathrm{~m}$ depth (the depth of the euphotic layer). The bottom topography used in the model is not the real topography shown on this figure but is based on the UNESCO topography data base. Also, in the model, Sect. 1 is located in a region where the depth varies between $100 \mathrm{~m}$ and $150 \mathrm{~m}$.

elevation induced by river runoff (Stanev and Beckers, 1999). The model uses a refined turbulent closure scheme defined by the turbulent kinetic energy and a mixing length which is calculated algebraically from a parametric neutral mixing length formulation modified by stratification effects. The density field is computed from the model temperature and salinity fields using a standard state equation for the sea water. Subgrid scale processes are parameterized by a laplacian operator with a horizontal diffusion coefficients of $500 \mathrm{~m}^{2} \mathrm{~s}^{-1}$ for momentum and $50 \mathrm{~m}^{2} \mathrm{~s}^{-1}$ for scalars. The GHER general circulation model has been successfully applied to explore the general circulation of the Bering Sea (e.g. Deleersnijder and Nihoul, 1988), the Mediterranean Sea (e.g. Beckers, 1991), the North Sea (e.g. Delhez, 1996), and, more recently, the Black Sea (e.g. Grégoire et al., 1998, 2004; Stanev and Beckers, 1999; Beckers et al., 2002).

\subsection{The ecosystem model}

The biogeochemical model describes the nitrogen cycling through the pelagic foodweb (all the biogeochemical state variables are expressed in $\mathrm{mmol} \mathrm{Nm}^{-3}$ except benthic detritus which are expressed in mmol $\mathrm{N} \mathrm{m}^{-2}$ ) and its state variables are defined according to the recommendations of the GLOBEC Numerical Modeling group as those which are thought to be necessary and sufficient to characterize the main features of the ecosystem response to a 3D environment at seasonal scales (GLOBEC, 1997). It is described by a 6 aggregated variables defined on the base of the functional role played in the trophic dynamics by planktonic populations: the phytoplankton and zooplankton biomass without reference to species, total pelagic detritus (lumping together dissolved and particulate dead organic matter), nitrate, ammonium and benthic detritus. The phytoplankton $(\varphi)$ represents all the primary producers. All the heterotrophs with a size ranging between $2 \mu \mathrm{m}$ and $2 \mathrm{~mm}$ are described by the zooplankton compartment $(z)$. The dead organic matter (particulate and dissolved) $(\omega)$ is described by the detritus compartment. The bacterial loop has been short-circuited since the timescales associated to bacterial growth are usually shorter than the other modeled time scales. It is of course a simplification but this short-circuiting is often done in 3D models and gives very good results. This simplification can be justified by the high efficiency of the microbial loop of the Black Sea's oxygenated waters (e.g. Sorokin, 1983; Karl and Knauer, 1991). Also, particulate organic material is directly converted to ammonium. Finally, the sediments are described by the benthic nitrogen pool $\beta_{n}$. 


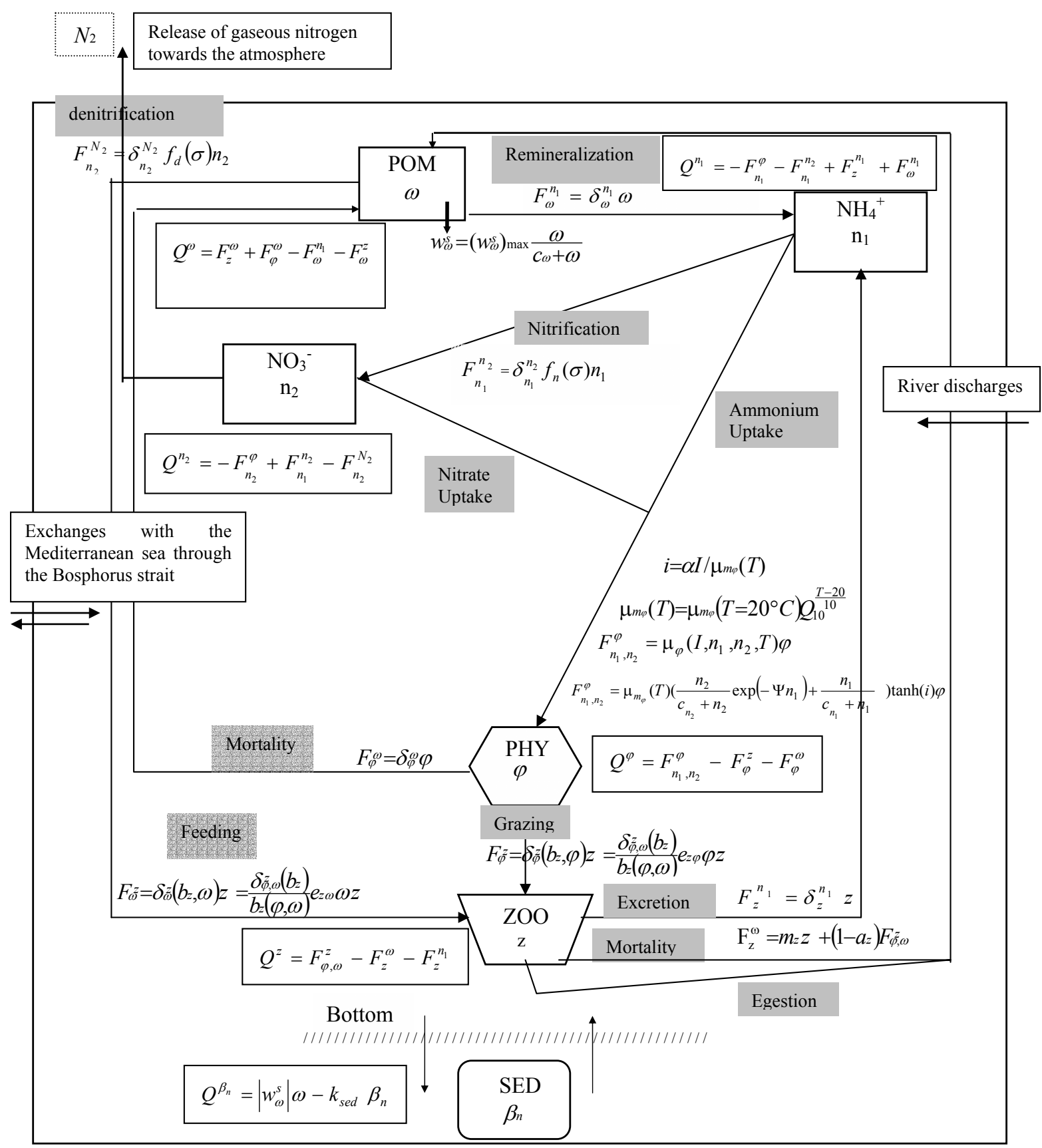

Fig. 2. Schematic representation of the ecosystem model. All the interaction terms are written on the arrows and are described in the Appendix $1 . F_{i}^{j}$ is the nitrogen flux issued from the state variable $i$ and going to the state variable $j . Q^{y}$ is the production/destruction term of the biogeochemical state variable $y$.

A schematic representation of the ecosystem model with all the interaction terms written on the arrows is given in Fig. 2. The evolution equations of the biogeochemical state variables and the mathematical formulation of the biogeochemical interactions are described in extenso Grégoire et al. (2004) and are summarized in the Appendix 1. The initial and boundary conditions used to force the hydrodynamical and biogeochemical models are described in the Appendix 2.
The estimation of biogeochemical parameters is based on available observations and studies (e.g. Oguz et al., 1996, 1998; Ozsoy et al., 1998) realized in the Black Sea or in other similar environments such as the Baltic Sea and the North Sea. Since, in a 3 D frame, one year of integration takes about 3 days of computation, some preliminary sensitivity studies are made with a box version of the model to determine the key parameters on the outcome of the ecosystem 
model (e.g. the sedimentation velocity, the maximum grazing rate). Once these parameters are known, the calibration of the 3D model consists essentially in adjusting them by a series of sensitivity experiments until the simulations show a good agreement with the available observations set.

\subsection{Implementation of the model}

The mathematical model offers a 3D view of the marine system and is formulated in the so-called $\sigma$-coordinate system to follow the bathymetry as closely as possible (a two-fold $\sigma \mathrm{t}$ coordinate system is used in regions of large bathymetric variations and of large depths). The numerical resolution is achieved through the 3D-finite differencing method on an Arakawa C-grid. To simulate the general circulation and associated synoptic structures, the domain is covered with a $15 \times 15 \mathrm{~km}$ horizontal numerical grid and 25 vertical $\sigma$-layers. The model marginally solves the rossby radius of deformation in the Black Sea which is about $20 \mathrm{~km}$. The spacing of the vertical layers is adjusted to offer a finer resolution in the vicinity of the surface and of the thermocline (the thickness of the vertical layers is about $5 \mathrm{~m}$ in the upper $30 \mathrm{~m}$ and $10 \mathrm{~m}$ down to $100 \mathrm{~m}$ ).

A centered-space differencing scheme is used to discretize the horizontal and vertical diffusion terms while an hybrid scheme, combining a centered and a streamline upwind discretization scheme is used for the advection (horizontal and vertical) terms. An explicit time step scheme is used to discretize horizontal fluxes while an implicit scheme is used on the vertical avoiding computational instabilities which may arise due to the use of a fine vertical resolution in the surface and bottom layers. The mode splitting technique is used to solve the equations of the rapidly evolving surface gravity waves (Madala and Piacsek, 1977). The resolution of a particular equation is done using the most recent value for each variable. The discretization of the production/destruction term of each biological state variable is based on a Patankar technique (Patankar, 1980). An explicit scheme is used for the production term while the destruction term is linearly implicitly discretized. Then, disregarding the denitrification term which represents a definitive nitrogen loss for the system, the sum of all the biogeochemical interaction terms is not strictly equal to zero as it should be if the system was fully numerically conservative. With a totally explicit numerical scheme, the sum of all the biogeochemical interaction terms would be exactly zero after discretization. However, an explicit scheme is completely unstable whatever is the time step of integration. To reduce the artificial production/destruction of matter, the dominant biological fluxes (i.e. the phytoplankton growth rate, the grazing rate) have to be computed at a given time-step consistently and therefore, the sequence of integration of the biogeochemical equations corresponds to the sense of the flux of matter in the ecosystem (i.e. inorganic nitrogen, phytoplankton, zooplankton, detritus). To quantify the conservation properly of the numerical scheme used in this study, one computes the evolution of the sum of the biogeochemical interaction terms (disregarding the denitrification term). It has been found that with a time step of $1 \mathrm{~h}$, the annual mean value of this sum is at maximum by two to three orders of magnitude lower than the typical value of the interaction terms. The maximum values are found in regions particularly active from a biological point of view and characterized by rapid fluctuations in the biogeochemical constituents on time scales comparable to the time step of integration (e.g. the Danube's discharge area, the western coast). Also, integrated over the whole basin and year, this artificial creation/destruction of matter due to the non-perfect numerically conservativity of the model was estimated to represent $1.3 \%$ of the order of magnitude of annual basin-wide integrated biogeochemical fluxes.

\subsection{Transient adjustment}

After ten years of integration of the physical model, the amplitude of the seasonal cycle is more or less established in response to the imposed external forcings and to the internal processes in the system. During the 10-year spin-up, the annual mean vertical stratification does not show substantial trends and remains close to the initial data. After this spin-up time, the hydrodynamical model is in balance and the basin inventory of water and salt remain constant over the annual cycle (Stanev and Beckers, 1999). This does not mean that trends are totally absent but, at the scale of our study (i.e. the seasonal cycle), the small trends, which may be potentially important for paleoceanography, could not significantly affect the results of the model. Using the results of the tenth year of integration of the physical model, the biological model of the upper layer ecosystem is then integrated to obtain almost repetitive yearly cycles of the biological variables (this is the case after three years of integration).

The quantitative measure of testing the attainment of the cyclical state is to check whether the 3D integrated (i.e. over the two horizontal directions and over the vertical) total nitrogen content, $\mathrm{N}_{T}\left(=n_{1}^{+} n_{2}^{+} \varphi+z+\omega+\beta_{n}\right)$ is approaching to a constant value over the annual cycle. This requires a perfect equilibrium between the nitrogen sources (i.e. the rivers and the Mediterranean inputs) and sinks (i.e. the denitrification, the export towards the anoxic layer and Mediterranean Sea). Since the river inputs and the Mediterranean exchanges are almost entirely imposed from the data (in the Bosphorus Strait, nutrients profiles measured in-situ are imposed, see Appendix 2; for the water fluxes, the fluxes give a water budget in equilibrium), the obtainment of an equilibrium solution will depend essentially on the ability of the model to represent adequately the amplitude of denitrification and sedimentation towards the deep waters. However, it is well known from sediment trap analysis and modeling studies that the amount of organic matter sedimenting towards the deep basin represents only a few percents of the amount of organic matter produced by photosynthesis (e.g. Karl and Knauer, 1991; 
Denitrification : 450,000

$(=67 \%$ of the annual river inorganic nitrogen load $)$

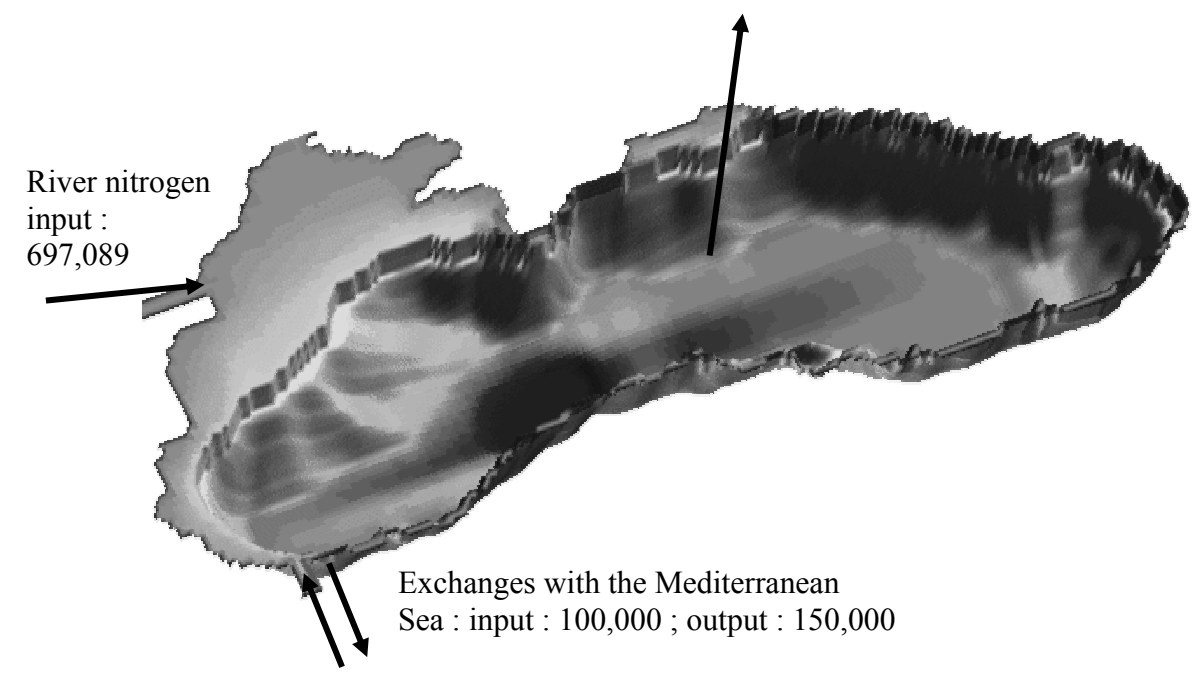

Fig. 3. Basin wide integrated annual nitrogen budget (in $\mathrm{t} \mathrm{N} \mathrm{yr}^{-1}$ ). The balance of these different sources and sinks gives an annual gain of nitrogen of $197 \times 10^{3}$ t. This budget would be equal to zero if the model was fully stationary.

Oguz et al., 1999; Grégoire and Lacroix, 2003). Therefore, to reach a steady state, the modelled denitrification process occurring in the water column should be able to eliminate a high percentage of the huge river nitrogen inputs. Figure 3 gives the different terms of the model estimated basin wide integrated annual nitrogen budget (in $\mathrm{t}_{\mathrm{N} \mathrm{yr}^{-1}}$ ). The basin wide nitrogen budget established from model results is not in equilibrium The nitrogen content of the whole basin (mainly the nitrate content) increases by $3 \%$ each year of integration. Figure 3 shows that the denitrification process constitutes the primary loss of nitrogen in the Black Sea with an estimated annual loss of free nitrogen of about $4.5 \times 10^{5} \mathrm{t}$. Therefore, $67 \%$ of the total annual load of inorganic nitrogen brought into the shelf by the rivers is irreversibly lost by denitrification (the annual load of inorganic nitrogen brought by the rivers equals 671,169). This last value is lower than the estimation of $75 \%$ made by Konovalov et al. (2000) with a budget model. Integrating over the whole basin the results of a 1D model, Yakushev and Neretin (1997) estimated to $10^{6} \mathrm{t}$ the annual amount of free nitrogen produced by denitrification. Thus, the model seems to underestimate the basin wide free nitrogen production due to denitrification as a result of the incapacity of the foodweb represented by the model to assimilate all the nitrate discharged by the rivers (this point will be clarify in Sect. 3.2). However, it should be noted that, the amount of nitrogen eliminated by denitrification is strongly linked to the input of inorganic nitrogen by the rivers. The model considers that every year the rivers introduce $617 \times 10^{3} \mathrm{t}$ of inorganic nitrogen. This value lies in the lower range of the observed estimates which are between $600 \times 10^{3} \mathrm{t}$ and $10^{6} \mathrm{t}$. We do not know for which value of the river discharge, Yakushev and Neretin (1997) estimated the Black Sea free nitrogen production to $10^{6} \mathrm{t}$. Therefore, we can suspect that the increase of the nitrate content after each year of integration is due to the incapacity of the ecosystem model to incorporate the totality of the river nitrate input in the upper layer organic matter cycle. Most of this unconsumed nitrate accumulates in the surface layer and does not reach the transitional layer to be eliminated by denitrification. It should also be noted that the increase of the nitrate inventory can be due to the non representation of the denitrification process as a process of benthic remineralization on the shelf. In the model, PON reaching the shelf sediments is totally remineralized. No burial and denitrification have been represented. In Gregoire and Friedrich (2004), it has been found that benthic denitrification occurring on the shelf sediments may be an important pathway of nitrogen elimination in the Black Sea. Integrating over the whole shelf and year, some punctual measurements obtained in summer 1995 and spring 1997 in the framework of the EU EROS 21 project, they obtained that about $60 \%$ of the PON flux reaching the shelf sediment may be eliminated by denitrification against about $8-17 \%$ for burial. With these values, about $50 \%$ of the annual load of inorganic nitrogen discharged by the Danube is lost through denitrification and burial. Although these last values can be criticized because they are obtained by integrating over the whole shelf and year some punctual measurements realized during a few weeks, they suggest that benthic denitrification is important. 

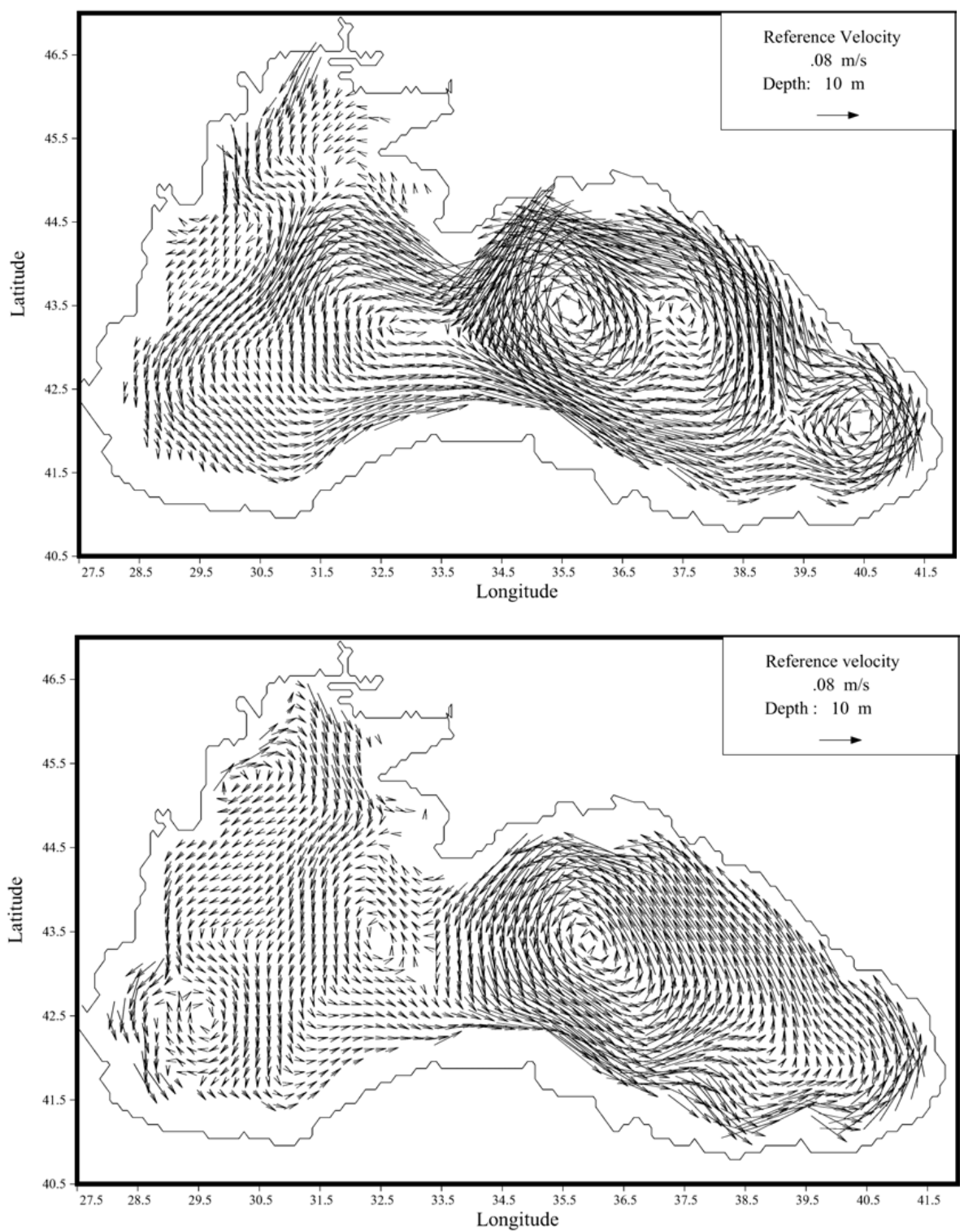

Fig. 4. Horizontal distribution of the general circulation simulated at $10 \mathrm{~m}$ in January (top) and in July (bottom) (currents in $\mathrm{m} \mathrm{s}{ }^{-1}$ ).

\section{Model results}

\subsection{The hydrodynamics}

A detailed description of the Black Sea's hydrodynamics simulated by the model is given in Grégoire et al. (1998) and Stanev and Beckers (1999). Here the main characteristics of the general circulation and of the frontal system are described stressing the aspects of the hydrodynamics that may affect the ecodynamics.

A basin scale, coherent, cyclonic boundary current is the main feature of the Black Sea general circulation (e.g. Stanev, 1990; Oguz et al., 1992, 1993; Stanev and Beckers, 1999). This cyclonic circulation results essentially of the cy- clonic wind pattern (positive curl of wind stress) but is also driven by the large scale hydro-thermodynamic forcing (surface and lateral buoyancy) and is controlled by the topography (e.g. Stanev, 1990). The mean position of the main surface current coincides approximately with the position of the continental slope, but important deviations are observed due to eddy variability, direct impact of atmospheric forcing or interannual variability. This cyclonic type of circulation dominates the vector plots of Fig. 4, but shows pronounced seasonal dependency, which is important for the transport of plankton and other biogeochemical components.

The shallow north-western shelf constitutes the coldest part of the Black Sea throughout the year (e.g. Ozsoy and Unluata, 1997; Ginzburg et al., 2001) and receives the fresh 

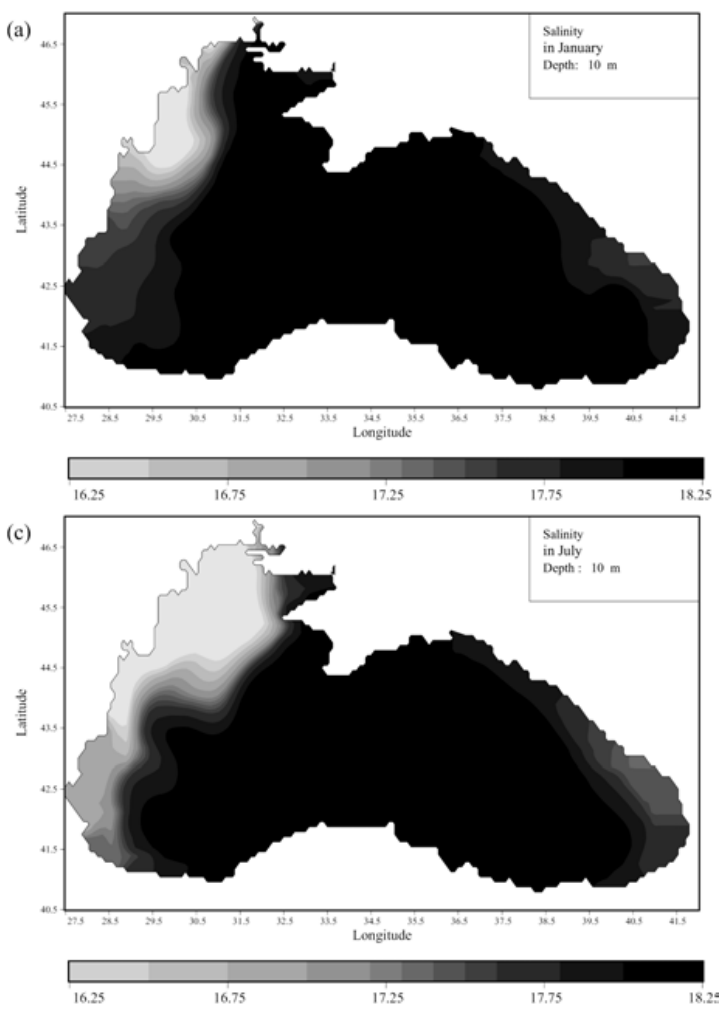

(b)

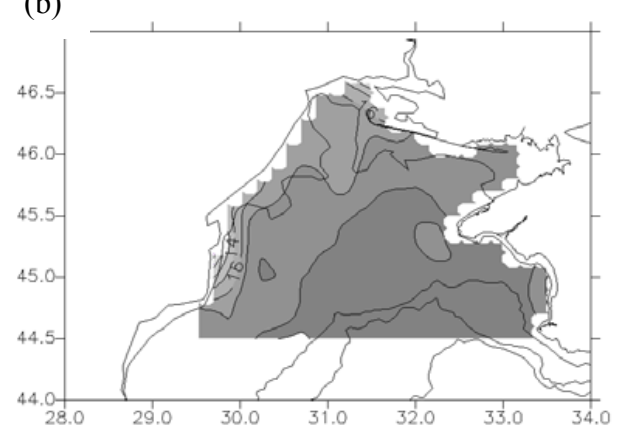

(d)

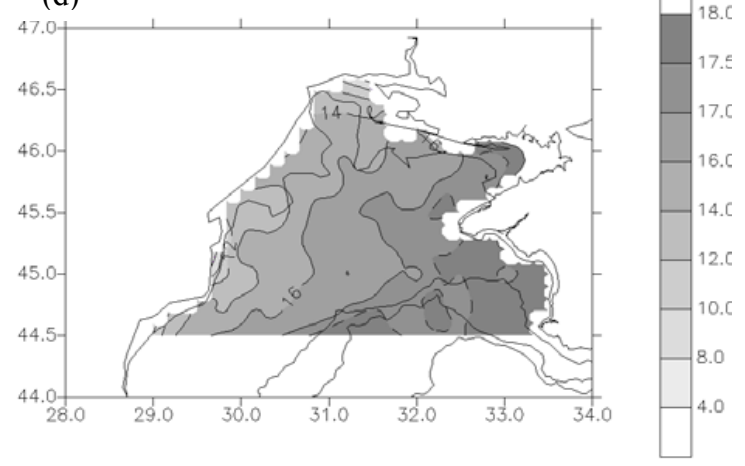

Fig. 5. Horizontal salinity distribution at $10 \mathrm{~m}$ in January: (a) and (b), in July: (c) and (d) simulated by the model (left) and reconstructed from in-situ data (right, S. Konovalov, Marine Hydrophysical Institue, personal communication, 1998).

water inputs of the Danube, Dnestr and Dnepr rivers. This leads to the formation of a strong haline front which can be observed during the whole year with seasonal modifications in its intensity and structure resulting mainly from the pronounced seasonal variability of the north-western shelf circulation (Fig. 5). This strong haline front confines river waters along the western coast and prevents the mixing between the coastal waters and the more saline open sea waters characterized by a salinity of $\approx 18-18.2$.

The circulation in the central and eastern parts of the sea remains relatively stable during the year, and the patterns do not show reversals of the current. On the contrary, the variability of the circulation is very pronounced between the main gyre and the coast, and in particular, on the northwestern shelf. This variability is illustrated by the presence of semi-permanent eddies, by the ejection of filaments generated by baroclinic instabilities at the frontal interface and by the reversal of the surface current of the north-western shelf at the end of spring until the end of fall. This reversal of the flow has an important impact on the distribution of the primary production of the area because it transports the rich nutrient Danube's water towards the north-eastern part of the shelf (e.g. Grégoire et al., 2004). This north-east extension of the low salinity river waters on the shelf at the end of spring has also been revealed by in-situ data (Fig. 5).

\subsection{The ecodynamics}

Both model results and observations illustrate a highly complex spatial variability of the phytoplankton annual cycle imparted by the horizontal and vertical variations of the physical and chemical properties of the water column. The frontal interface separating river waters and open sea waters is primarily a boundary between the eutrophic shelf waters and the less productive open sea waters. On the north-western shelf, the model shows that the seasonal evolution of the productive waters illustrated by the satellite images is primarily connected to the seasonal variation of the north-western shelf circulation that leads to modification in the transport of the rich nutrients Danube's waters. In all the regions, the phytoplankton annual cycle is characterized by the presence of a winter-early spring bloom. This bloom precedes the onset of the seasonal thermocline and occurs as soon as the mixing layer depth reduces and becomes comparable or shallower than the euphotic layer depth. In the Danube's discharge area and along the western coast, where surface waters are almost continuously enriched in river nutrient, the phytoplankton development is sustained during the whole year at the surface with seasonal modifications in its intensity. On the contrary, in the central basin, the primary production in the surface layer relies essentially on nutrients being entrained in 


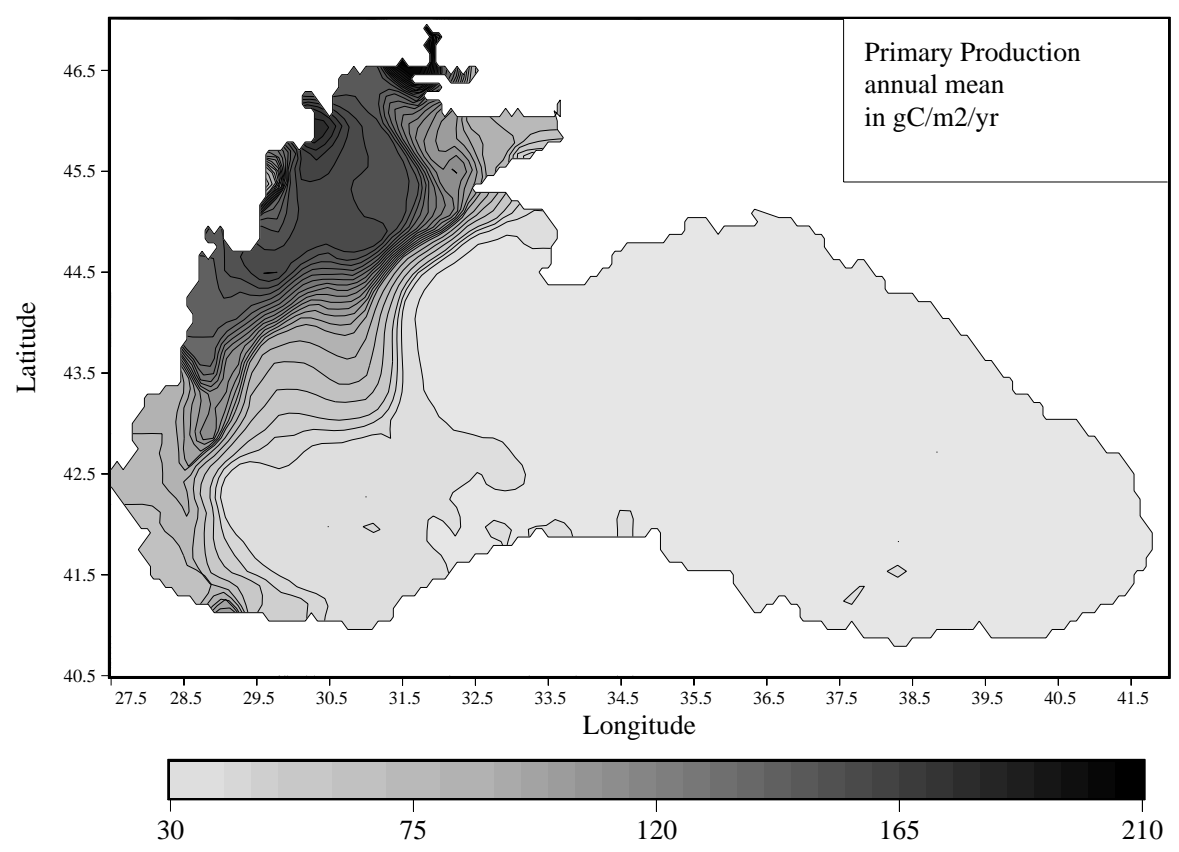

Fig. 6. A composite picture of the horizontal distribution of the vertically integrated annual gross primary production ( $\mathrm{gC} \mathrm{m}^{-2} \mathrm{yr}^{-1}$ ) computed by the model.

the upper layer from below and a winter-early spring bloom is simulated in agreement with field observations. At the end of spring and in summer, the maximum development of the phytoplankton is observed at depth, below the thermocline, except at the Danube's mouth where it occurs at the surface all over the year.

The qualitative comparison of model results with SeaWiFS satellite data shows that the model reproduces reasonably well the space-time evolution of the phytoplankton distribution. On a quantitative point of view, however, the model underestimates the phytoplankton biomass in the Danube's discharge area and along the western coast. In these regions, the extremely high nutrient concentrations allows the phytoplankton growth at almost nutrients saturation conditions. However, as soon as the simulated phytoplankton biomass reaches a threshold value, the zooplankton develops and maintains a strong control on the phytoplankton development. This deficiency is typical of simple ecosystem models considering only one phytoplankton and one zooplankton compartment which may overestimate the grazing pressure. Similar conclusions have been found earlier by Sarmiento et al. (1993) in their North Atlantic model, and by Oguz et al. (1999) in their Black Sea model.

The plankton annual cycle simulated by the model is described in extenso in Gregoire et al. (2004) and is compared with satellite and in-situ observations.

\subsection{Primary production}

The Black Sea is known as a region of moderate to high biological productivity: the north-western shelf into which the major Black Sea's rivers flow is characterized by the highest productivity while the central basin, where the biological production relies essentially on nutrients being entrained from below by the vertical mixing, is a region of moderate productivity (Fig. 6). Using an algal carbon to nitrogen ratio of $\sim 8.5$ for nitrogen limited ecosystem, the model estimates to $130 \mathrm{~g} \mathrm{C} \mathrm{m}^{-2} \mathrm{yr}^{-1}$ the vertically integrated primary production of the whole basin which is lower than the estimates of $200 \mathrm{~g} \mathrm{C} \mathrm{m}^{-2} \mathrm{yr}^{-1}$ made by Sorokin (1983).

\subsubsection{Primary production of the central basin}

The vertically integrated annual primary production estimate of $40 \mathrm{~g} \mathrm{C} \mathrm{m}^{-2} \mathrm{yr}^{-1}$ from the model lies in the lower values of the observed estimates which are between $40 \mathrm{~g} \mathrm{C} \mathrm{m}^{-2} \mathrm{yr}^{-1}$ (Finenko, 1979) and $90 \mathrm{~g} \mathrm{C} \mathrm{m}^{-2} \mathrm{yr}^{-1}$ (Sorokin, 1983) from the various measurements in the central part of the sea. The model estimate is about the third of the estimate of $150 \mathrm{~g} \mathrm{C} \mathrm{m}^{-2} \mathrm{yr}^{-1}$ made by Vedernikov and Demidov (1993). However, according to Oguz et al. (1999), this last value is misleading, since it is based on a multi-year composite data set, which includes more than one set of late winter-early spring bloom events that occurred on different days in different years and therefore these measurements may overestimate the annual primary production rate. 


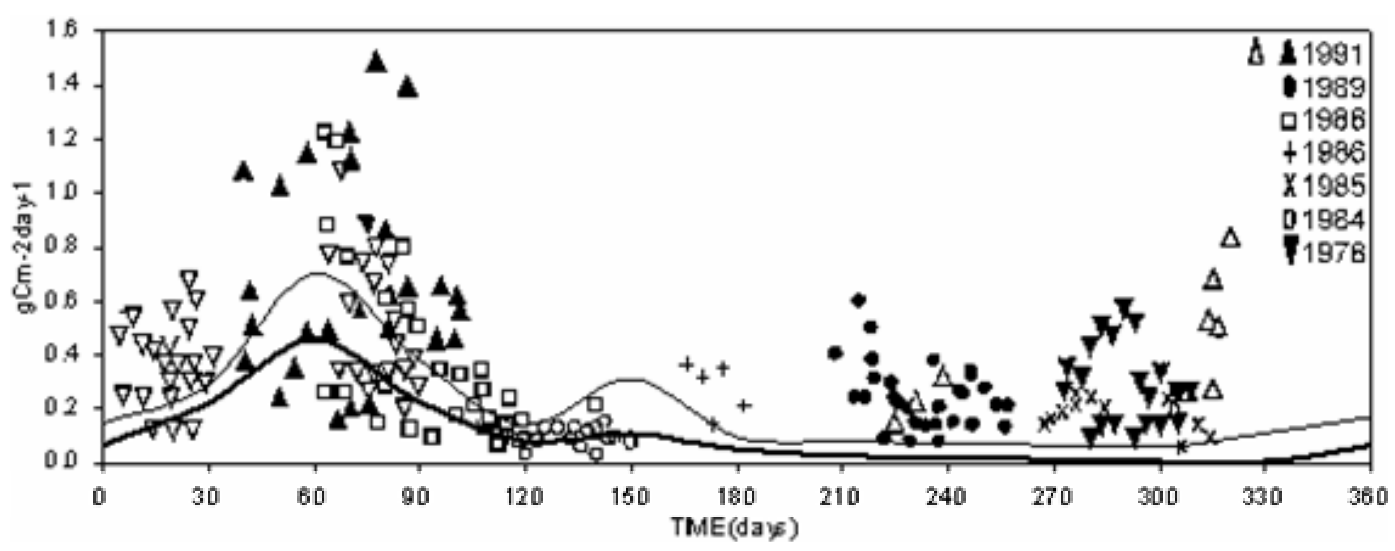

Fig. 7. A composite picture of the vertically integrated gross primary production seasonal cycle $\left(\mathrm{g} \mathrm{C} \mathrm{m}^{-2} \mathrm{~d}^{-1}\right)$ compiled from different data sources obtained for different stations within the central Black Sea and at different years $(\triangle \boldsymbol{\Delta} 1991, \bigcirc 1989, \square 1988,+1986, \times 1985, \bigcirc$ $1984, \boldsymbol{\nabla}$ 1978). The data are redrawn from Vedernikov and Demidov (1993) (picture modified from Oguz et al., 1996). The continuous lines show the model predicted primary production. In bold, mean values for the central basin and in normal line, values for the eastern main gyre.

The annual cycles of the vertically integrated primary production produced by the model for the whole central basin and for the region of the eastern main cyclonic gyre (mean spatial profiles) are compared with the values of a series of measurements made between 1978-1991 and reported by Vedernikov and Demidov (1993) (Fig. 7). The highest values of $0.7 \mathrm{~g} \mathrm{C} \mathrm{m}^{-2} \mathrm{~d}^{-1}$ and $0.45 \mathrm{~g} \mathrm{C} \mathrm{m}^{-2} \mathrm{~d}^{-1}$ for respectively the eastern gyre and the whole central area are simulated in winter-early spring (February-March) when the vertical flux of inorganic nutrients through the euphotic layer reaches its maximum (see Fig. 15). These values compare reasonably well with the in-situ measurements of $0.2-1.5 \mathrm{~g} \mathrm{C} \mathrm{m}^{-2} \mathrm{~d}^{-1}$ made by Vedernikov and Demidov (1993) (Fig. 7) as well as with the observations of $0.2-0.96 \mathrm{~g} \mathrm{C} \mathrm{m}^{-2} \mathrm{~d}^{-1}$ (mean $0.4 \mathrm{~g} \mathrm{C} \mathrm{m}^{-2} \mathrm{~d}^{-1}$ ) realized by Mikaelyan (1995) at different stations of the central basin for the period FebruaryMarch 1991. Model results show that the primary production is at maximum in the centers of the main cyclonic gyres of the central basin and decreases towards the periphery. The winter-early spring bloom is followed by a secondary peak in late spring (May-June) with values between $0.31 \mathrm{~g} \mathrm{C} \mathrm{m}^{-2} \mathrm{~d}^{-1}$ for the eastern gyre and $0.11 \mathrm{~g} \mathrm{C} \mathrm{m}^{-2} \mathrm{~d}^{-1}$ for the whole central basin. These values are in agreement with typical measurements for this period which are of $0.1-$ $0.6 \mathrm{~g} \mathrm{C} \mathrm{m}^{-2} \mathrm{~d}^{-1}$ (Vedernikov and Demidov, 1993) and 0.3$0.5 \mathrm{~g} \mathrm{C} \mathrm{m}^{-2} \mathrm{~d}^{-1}$ in the center of the western main cyclonic gyre in May 1988 (Karl and Knauer, 1991). The summerearly fall period is found to be the less productive period characterized by values less than $0.1 \mathrm{~g} \mathrm{C} \mathrm{m}^{-2} \mathrm{~d}^{-1}$ (about $0.07 \mathrm{~g} \mathrm{C} \mathrm{m}^{-2} \mathrm{~d}^{-1}$ for the eastern gyre and $0.02 \mathrm{~g} \mathrm{C} \mathrm{m}^{-2} \mathrm{~d}^{-1}$ for the whole central basin) whereas the observations values vary from 0.2 to $0.6 \mathrm{~g} \mathrm{C} \mathrm{m}^{-2} \mathrm{~d}^{-1}$ in the same period (Vedernikov and Demidov, 1993). These recent estimations are much higher than the 1960's observations (Sorokin, 1983) which gave values between $0.05 \mathrm{~g} \mathrm{C} \mathrm{m}^{-2} \mathrm{~d}^{-1}$ and
$0.5 \mathrm{~g} \mathrm{C} \mathrm{m}^{-2} \mathrm{~d}^{-1}$ for the different stations within the central Black Sea. It is reported that the primary production in the central part of the sea has increased by a factor of 3 to 4 over the last 30 years (Sorokin, 1964; Stelmakh et al., 1998). The underestimation of the primary production in early fall by the model is likely due to the underestimation of the vertical mixing at this period. This period is characterized by the presence of weekly storms which are not adequately represented in the model although they are expected to enhance temporarily the upward flux of nitrate into the surface layer (Oguz et al, 1996). Indeed, since the model is forced at the air-sea interface by the mean wind stress at macroscale produced by a monthly mean wind and not, as it should be, by the mean wind stress including a quite significant component due to non-linear interactions of mesoscale winds, small scales events such as storms are not well represented and this leads to an underestimation of the production of turbulent kinetic energy at the surface. On the other hand, at the surface, temperatures values are relaxed towards climatological monthly mean values and this leads to an overestimation of surface temperatures. Therefore, the vertical mixing by convection is underestimated. Besides, it should be noted that using a relaxation scheme for the temperature to force the model at the surface instead of the heat fluxes underestimates the vertical penetration of the seasonal atmospheric signal. For instance, in spring, only the first upper $15 \mathrm{~m}$ are affected by the seasonal heating of the water column. As a result, in summer, the vertical extension of the thermocline is estimated to about $13 \mathrm{~m}$ while field observations give a vertical extension of about $30 \mathrm{~m}$. Also, the early-fall peak in primary production is delayed and only occurs in November-December when the intensification of the wind stress destroys the seasonal thermocline of the central basin. In November, the primary production increases and reaches in December $0.2 \mathrm{~g} \mathrm{C} \mathrm{m}^{-2} \mathrm{~d}^{-1}$ in the center of the 


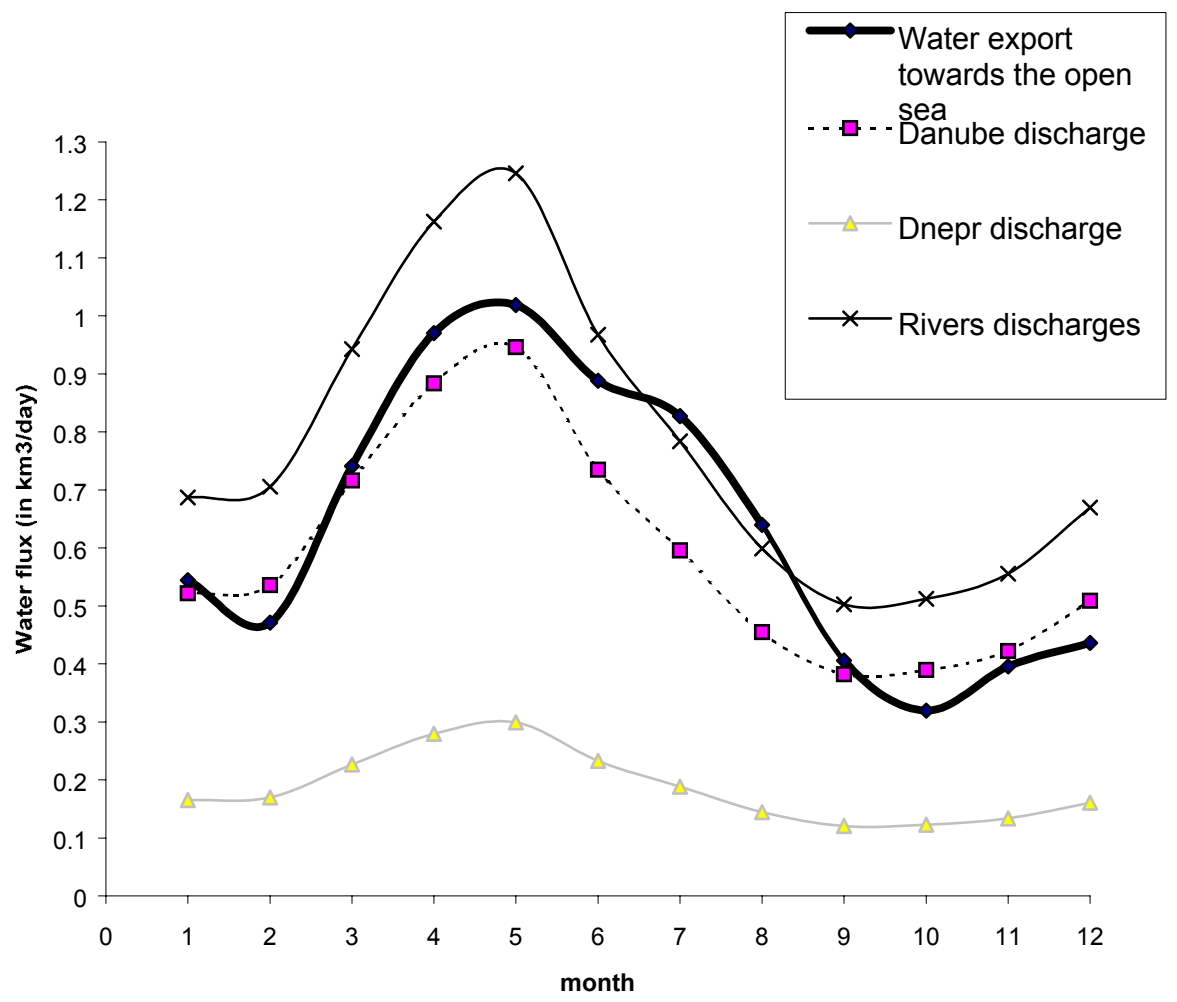

Fig. 8. Seasonal cycle of the river discharges (in normal line), the Danube's discharge (in dotted line), the Dnepr discharge (in grey) and of the water export towards the open sea (computed by the model) in $\mathrm{km}^{3} \mathrm{~d}^{-1}$.

eastern main cyclonic gyre which is slightly lower that the values of $0.36 \mathrm{~g} \mathrm{C} \mathrm{m}^{-2} \mathrm{~d}^{-1}$ obtained as an average of measurements from all stations in the central basin at the time of the autumn bloom (Vedernikov and Demidov, 1993).

\subsubsection{Primary production of the north-western shelf}

The model estimated vertically integrated annual primary production of $220 \mathrm{~g} \mathrm{C} \mathrm{m}^{-2} \mathrm{yr}^{-1}$ is in good agreement with the measurements of Sorokin (1983) which gave a value of $250 \mathrm{~g} \mathrm{C} \mathrm{m}^{-2} \mathrm{yr}^{-1}$. These last values are much higher than the total primary production of the Gulf of Lions in the Mediterranean Sea fed by the nutrients input of the Rhone river (annual nitrate input $=70000 \mathrm{t}$, about a tenth of the Danube's input) which is estimated between $77 \mathrm{~g} \mathrm{C} \mathrm{m}^{-2} \mathrm{yr}^{-1}$ and $106 \mathrm{~g} \mathrm{C} \mathrm{m}^{-2} \mathrm{yr}^{-1}$ (Tusseau et al., 1998).

Our model estimates of the annual primary production of the shelf and of the central basin are in good agreement with the observations made for different regions of the world by Ryther (1969) which give values of $50 \mathrm{~g} \mathrm{C} \mathrm{m}^{-2} \mathrm{yr}^{-1}$ for oceanic waters, $100 \mathrm{~g} \mathrm{C} \mathrm{m}^{-2} \mathrm{yr}^{-1}$ for coastal and neritic regions and $300 \mathrm{~g} \mathrm{C} \mathrm{m}^{-2} \mathrm{yr}^{-1}$ for upwelled waters.
3.4 Water and nitrogen exchanges between the northwestern continental shelf and the deep sea

The model allows us to quantify the monthly integrated fluxes of water and of any biogeochemical component at the shelf break represented by the vertical section shown in Fig. 1 (Sect. 1, surface $50 \mathrm{~km}^{2}$ ). The area located at the north of this section is characterized by a depth lower than $150 \mathrm{~m}$ and is considered representative for the Black Sea's north western shelf (volume: $4,7 \times 10^{3} \mathrm{~km}^{3}$, surface: $50 \times 10^{3} \mathrm{~km}^{2}$ ).

\subsection{Water transport fluxes}

The seasonal variations of the net water transport flux follow the annual cycle of the river discharges with a peak in May and a minimum in October when the river discharges reach respectively their maximum and minimum values (Fig. 8). Figure 9 displaying the different terms of the north-western shelf annual water budget shows that the global budget (which would be equal to zero if no error was made when diagnostically computing the water export through Sect. 1) is equal to $14 \mathrm{~km}^{3}$ and therefore, one estimates the relative error associated to the computation of the water export to about $6 \%$.

The space-time variability of the water transport flux through the shelf break is extremely high. For instance, the 


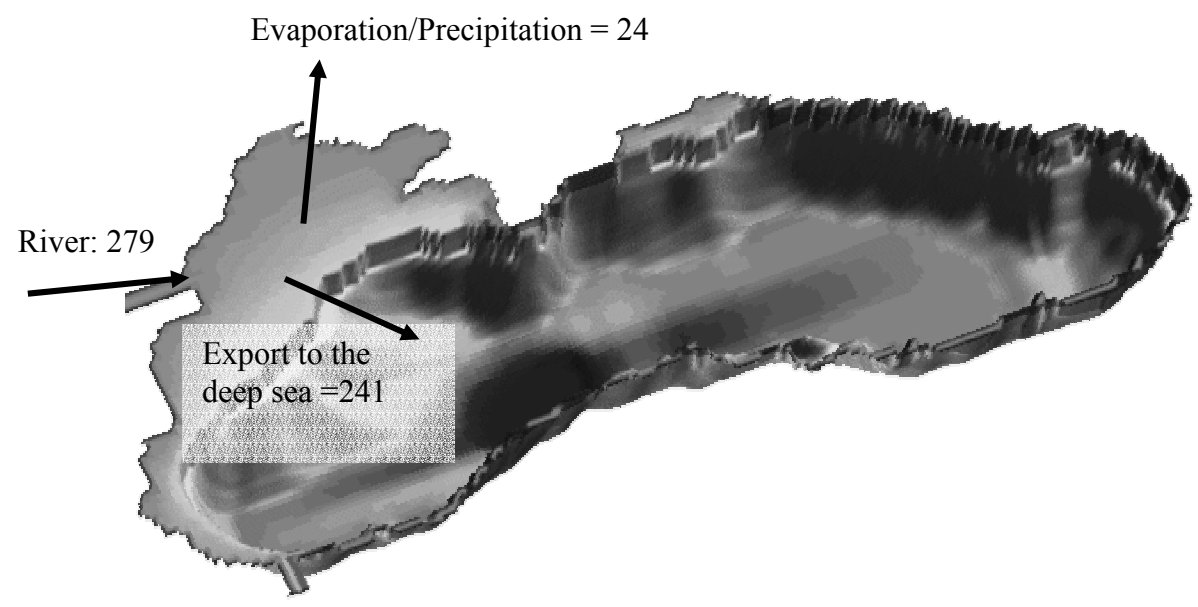

Fig. 9. Integrated annual water fluxes (in $\mathrm{km}^{3} \mathrm{yr}^{-1}$ ) for the north-western shelf area. The annual water budget of the shelf would be equal to zero if the export towards the open sea was exactly computed. The relative error on the computed export is estimated to $6 \%$.

comparison of Figs. 10a and $10 \mathrm{~b}$ illustrating respectively the vertical distribution through Sect. 1 of the annual mean water flux and of its standard deviation (showing the seasonal variability in the water transport flux) indicates that the standard deviation is comparable to the annual mean and is particularly high in the eastern part of the section due to the pronounced variability of the circulation in this area (Fig. 4). Indeed, from the end of spring until the end of fall, the circulation on the shelf is anticyclonic and a strong flux of water leaves the shelf in the eastern part while, in winter, the surface current reverses and becomes cyclonic and surface waters are transported onto the shelf from the open sea (Figs. 10c and d). In addition to this pronounced temporal variability, the spatial variability is also very high. The flux of water leaving the shelf is mainly concentrated in the upper $50 \mathrm{~m}$ while below, the water flux usually enters into the shelf. The spatial mean of the normal velocity to Sect. 1 is estimated to $-0.163 \times 10^{-3} \mathrm{~m} / \mathrm{s}$ (spatial mean value of the annual mean velocity field normal to Sect. 1) and is an order of magnitude lower than its standard deviation (showing the spatial variability in the water transport flux) of $0.5046 \times 10^{-2}$. Therefore, considering this pronounced variability, the error made on the water export calculation is totally acceptable.

\subsubsection{Nitrogen transport fluxes}

The annual cycle of the net nitrogen transport across the shelf break presents two peaks (Fig. 11). The first one, in AprilMay, is associated whith the major peak in the river discharges. The second one occurs in September and is not observed in the water transport flux (Fig. 8). This last peak occurs when the rich nitrate Danube's waters transported from the river's mouth by the anticyclonic shelf current reach the shelf break and penetrate into the western part of the central basin (Fig. 12e). As one can expect, the transport by diffusion is usually lower than the advection transport es- pecially during the second half of the year when the diffusion transport is almost by one order of magnitude lower than the advection flux (Figs. 12c and d). Also, the annual cycle of the total nitrogen transport follows approximately the cycle of the advection flux but is higher. Of course, the nitrogen transport is essentially determined by the nitrate transport. The net integrated (over the whole vertical section) advection and diffusion transports are both positive during the whole year (Fig. 11) because, on the one hand, the integrated water transport is also positive throughout the year and, on the other hand, the nitrogen concentrations of the shelf waters are much higher than in the open sea. The model shows that the annual nitrogen net loss for the shelf above $55 \mathrm{~m}$ reaches $610040 \mathrm{t}$. As for the water transport, the space-time variability of the nitrogen transport flux is highly pronounced. The spatial mean of the annual mean nitrogen transport is $-0.4044 \times 10^{-1} \mathrm{mmol} \mathrm{N} \mathrm{m}^{-2} \mathrm{~s}^{-1}$ and the standard deviation equals 0.102 . This variability is essentially communicated by the advection flux which has a spatial mean of $-0.2601 \times 10^{-1} \mathrm{mmol} \mathrm{N} \mathrm{m}^{-2} \mathrm{~s}^{-1}$ and a standard deviation of $0.98 \times 10^{-1}$ while the diffusion flux has a mean of $-0.144 \times 10^{-1} \mathrm{mmol} \mathrm{N} \mathrm{m}^{-2} \mathrm{~s}^{-1}$ and a standard deviation of $0.811 \times 10^{-2}$

This strong spatial and temporal variability of the nitrogen and water transport can be explained by the $3 \mathrm{D}$ complexity of the circulation along the shelf break. The variability of the north-western shelf circulation is mainly illustrated by the reversal of the surface current at the end of spring until the end of fall and the generation, at the Danube's mouth, of an anticyclonic eddy with a length scale of some tens of km (Fig. 4). Also, this suggests that it would be extremely delicate to apply a high resolution model to the shelf forced at the open sea by boundary fluxes computed by a coarse resolution model applied to the whole basin. 
(a)

Annual mean values
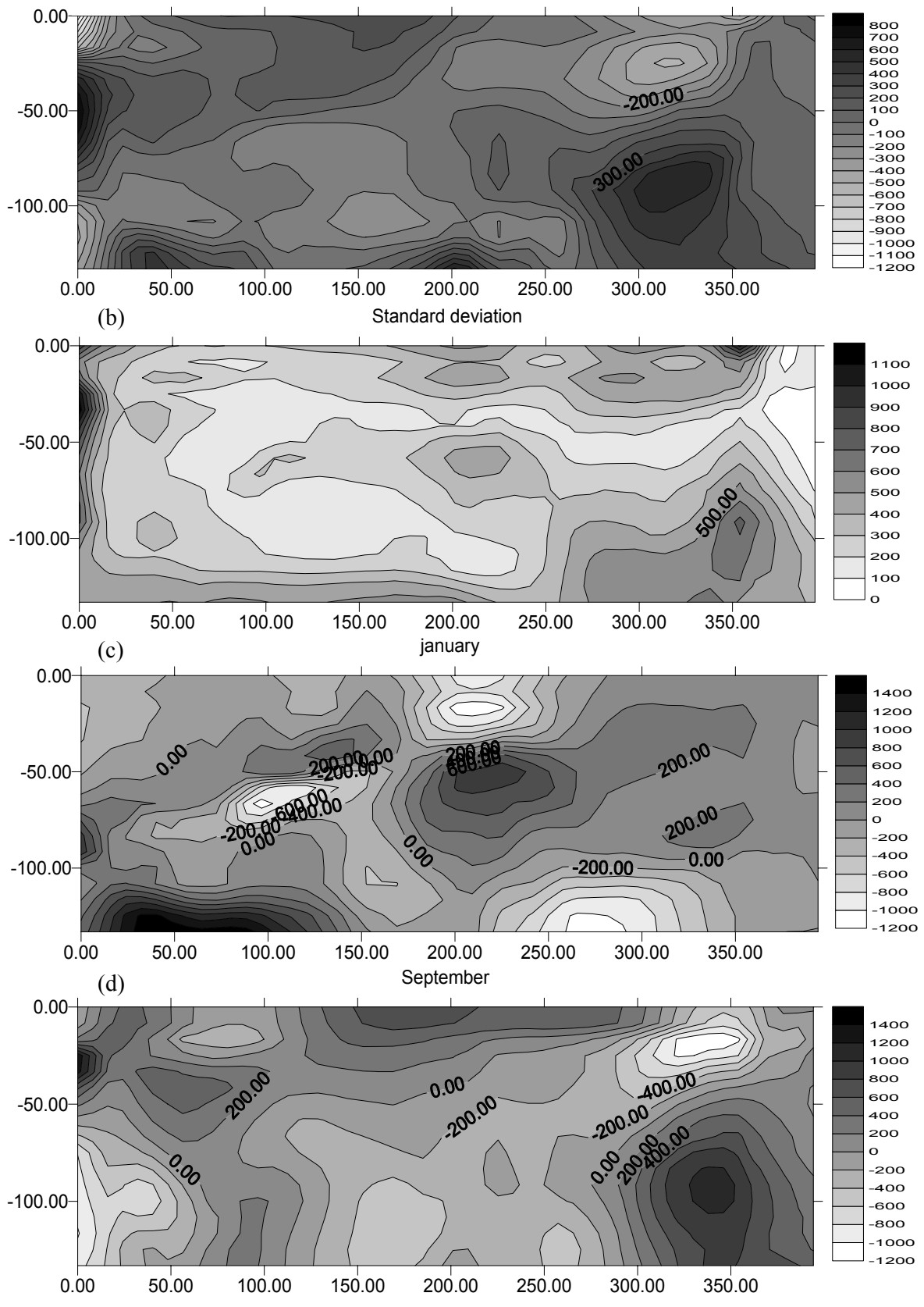

Fig. 10. Water flux Sect. 1 (in $\mathrm{km}^{3} \mathrm{~d}^{-1}$, a negative value is associated to an export of water from the shelf towards the deep basin) (a) annual mean field, (b) standard deviation of the annual mean field, (c) water flux in January and (d) in September. The abscises give the along-slope distance counted in $\mathrm{km}$ from the most western point of Sect. 1 (see Fig. 1).

\subsection{Nitrogen cycling on the north-western shelf}

The amount of nitrogen transferred by biogeochemical processes between the different modeled compartments has been quantified as well as the evolution over one year of integration of the nitrogen content of each compartment (results representative of the situation reached after five years of inte- gration) (Fig. 13). The annual nitrogen budget of the northwestern shelf implies an approximate balance between the variation of the nitrogen inventory of the shelf, the external input of total nitrogen by the rivers and the nitrogen transported at the shelf break. This balance is almost verified and one estimates the relative error on the diagnostic computation of the nitrogen export towards the open sea to about 


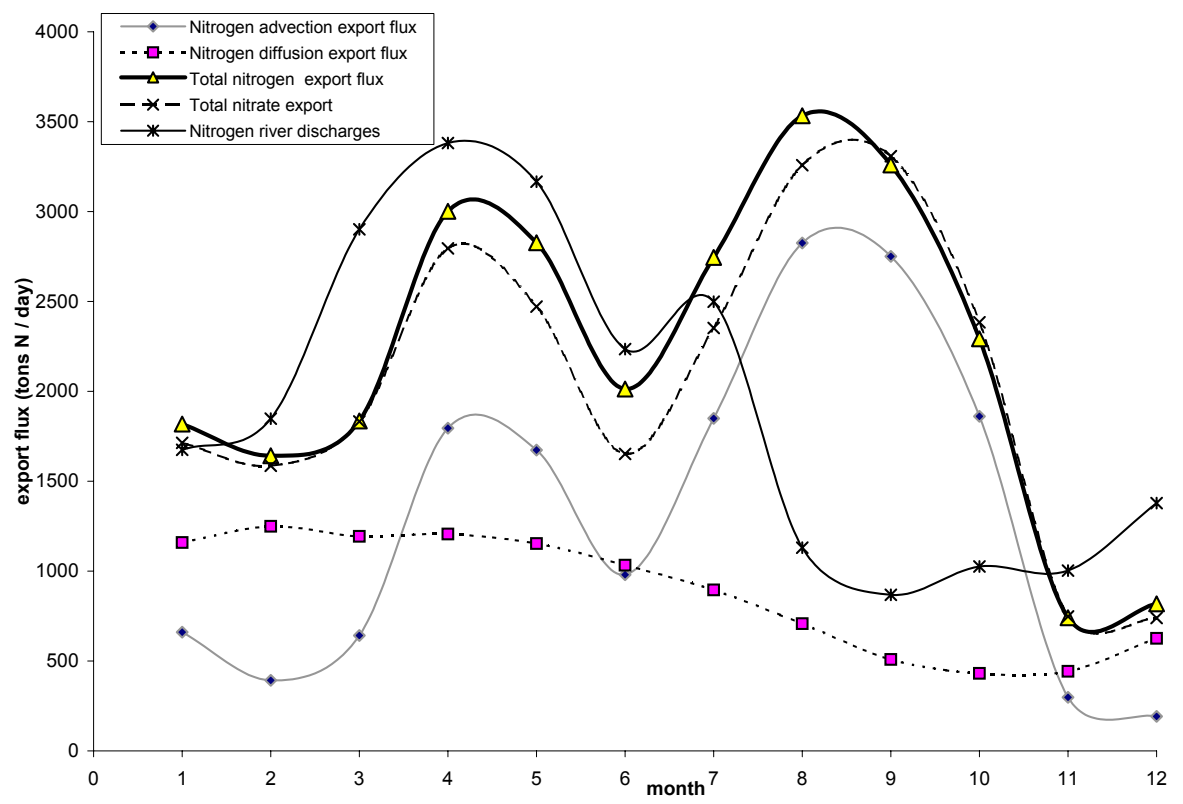

Fig. 11. Annual cycle of the nitrogen river discharges (in normal line), the total nitrogen export from the shelf towards the deep basin (in bold), the nitrogen export by horizontal advection (in grey) and diffusion (in dotted line) and the total nitrate export (in interrupted line) (in $\mathrm{t}$ $\left.\mathrm{N} \mathrm{d}^{-1}\right)$.

$5.6 \%$ which is in agreement with the estimated relative error on the water export.

The biological fluxes almost compensate each other and are the dominant terms of the nitrogen budget of each biogeochemical state variable. Indeed, the biological fluxes integrated over one year are at least by one order of magnitude (except for nitrate and benthic detritus) greater than the river discharges, the transport at the shelf break and than the nitrogen content of the biogeochemical compartment. This implies a short turnover time (from a few days to a hundredth of days for nitrate) for these compartments and thus, the possibility of fast changes in their nitrogen inventory caused by small changes in the rate of biogeochemical processes and also in the river discharges and the exchanges at the open sea. Therefore, the variation of the nitrogen content of each biogeochemical state variable after one year of integration, which is at maximum of $10 \%$ (for the nitrate), lies within the error bars of the biogeochemical model (associated to the non-fully conservative numerical discretization, see Sect. 2.3) and of the computed export.

The dominant biogeochemical fluxes are the nutrient uptake by phytoplankton, the grazing, the remineralization, the nitrification and the excretion. The loss of nitrogen by denitrification equals zero. The fluxes towards and from the sediments almost compensate and are at least by one order of magnitude lower than the other biogeochemical fluxes.

The budget condicates that the to-
tal primary production of the shelf
$\left(800 \times 10^{3} \mathrm{t} \mathrm{N} \mathrm{yr}^{-1}+726 \times 10^{3} \mathrm{tN} \mathrm{yr}^{-1}=1,526 \times 10^{3} \mathrm{t} \mathrm{N} \mathrm{yr}^{-1}\right)$

and the export of inorganic nitrogen towards the deep sea $\left(763 \times 10^{3} \mathrm{t} \mathrm{N} \mathrm{yr}^{-1}\right)$ are roughly compensated by the ammonium regenerated through the remineralization of detritus in the water column $\left(598 \times 10^{3} \mathrm{t} \mathrm{N} \mathrm{yr}^{-1}\right)$ and in the sediments $\left(174 \times 10^{3} \mathrm{t} \mathrm{N} \mathrm{yr}^{-1}\right)$ and through zooplankton excretion $\left(683 \times 10^{3} \mathrm{t} \mathrm{N} \mathrm{yr}^{-1}\right)$ plus the external input of total inorganic nitrogen into the shelf by the rivers $\left(671 \times 10^{3} \mathrm{t} \mathrm{N} \mathrm{yr}^{-1}\right)$. The recycling of organic matter in the water column through zooplankton excretion and detritus remineralization represents $84 \%$ of the total primary production, benthic recycling represents $11.4 \%$ of the total primary production and the river inorganic nitrogen discharge $44 \%$. $36 \%$ of the annual load of inorganic nitrogen brought by the rivers and remineralized in-situ is not consumed by the primary producers and is exported towards the deep sea. The nitrate and ammonium uptakes are respectively $800 \times 10^{3} \mathrm{t} \mathrm{N} \mathrm{yr}^{-1}$ and $726 \times 10^{3} \mathrm{t} \mathrm{N} \mathrm{yr}^{-1}$ which accounts $52.4 \%$ and $47.6 \%$ of the annual total primary production.

The model estimates the amount of organic matter remineralized in the Black Seas northwestern shelf sediments during a climatological year to be $182 \times 10^{3} \mathrm{t} \mathrm{N} \mathrm{yr}^{-1}$. This means $12 \%$ of the shelf integrated model estimated phytoplankton requirements in nitrogen over the year (Gregoire and Lacroix, 2003). Using a $\mathrm{C}: \mathrm{N}$ mass ratio of 7.8 for the rapidly sinking organic matter (Wijsman, 2001), the POC

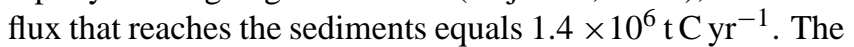
POM flux to the sediment was derived from the EROS21 observations performed in August 1995 and May 1997 on the shelf. The mass balance of organic matter decomposition 
(a)

Annual mean flux

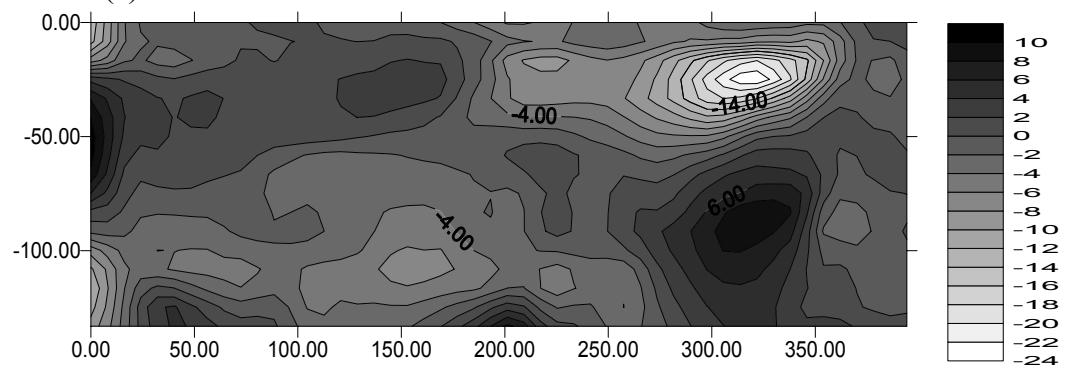

(b)

Standard Deviation

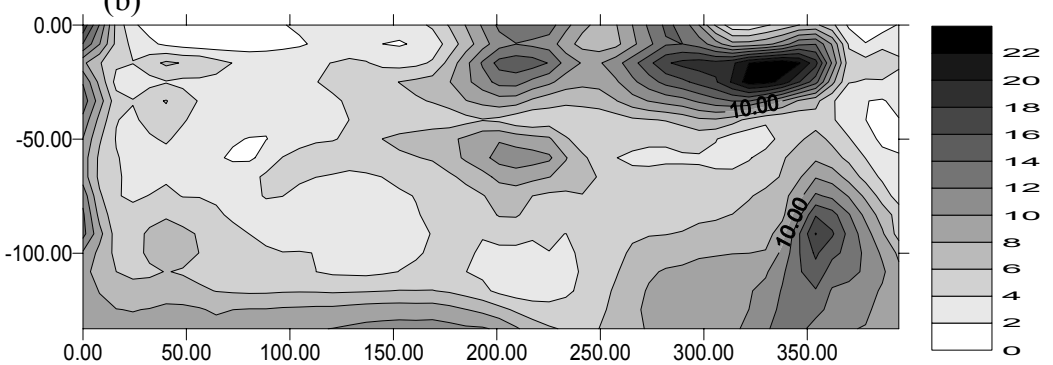

(c)

Advection flux : Annual mean values

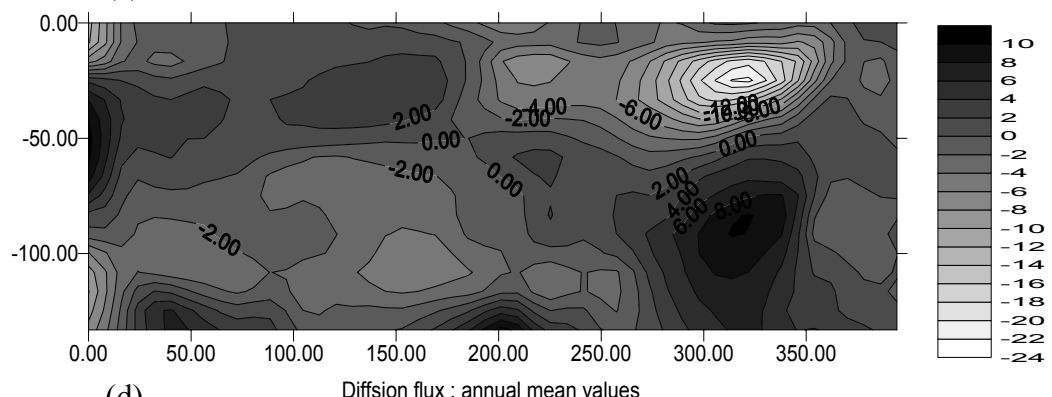

(d)

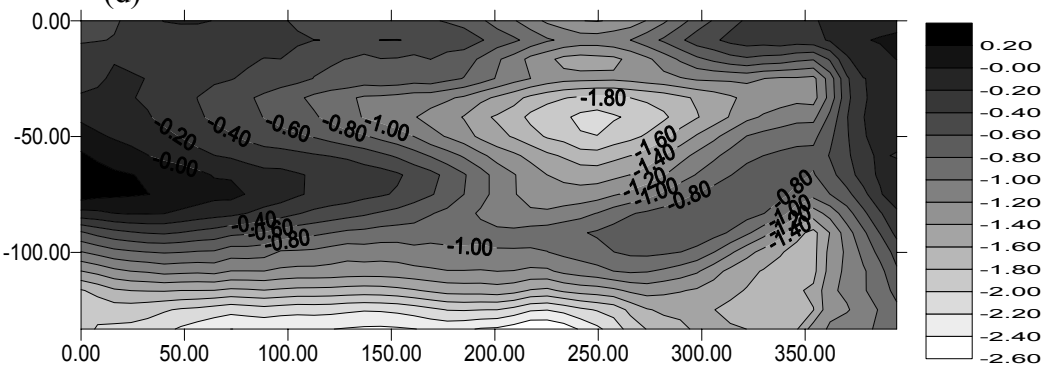

(e)

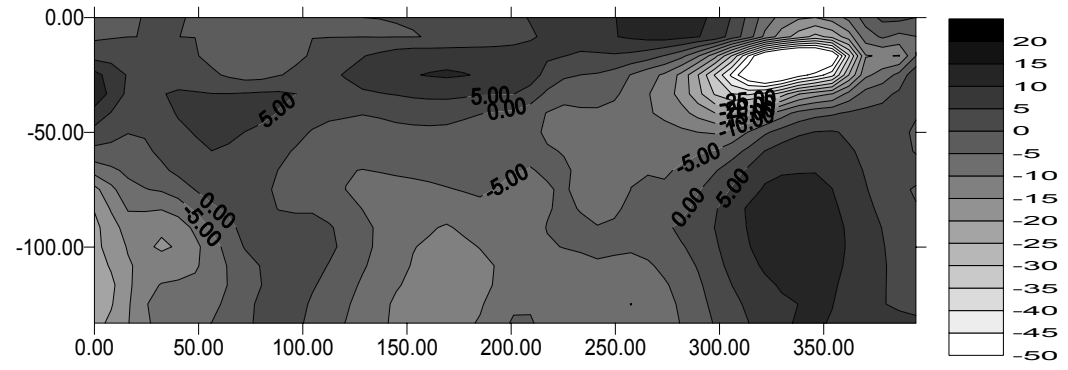

Fig. 12. Vertical distribution of the nitrate transport through Sect. 1 (in $\mathrm{t} \mathrm{N} \mathrm{d}^{-1}$, negative values are associated to an export towards the deep basin): (a) annual mean values, (b) standard deviation of the annual mean field, (c) nitrate export by horizontal advection and (d) diffusion, (e) total nitrate export in September. The abscises give the along-slope distance counted in km from the most western point of Sect. 1 (see Fig. 1). 


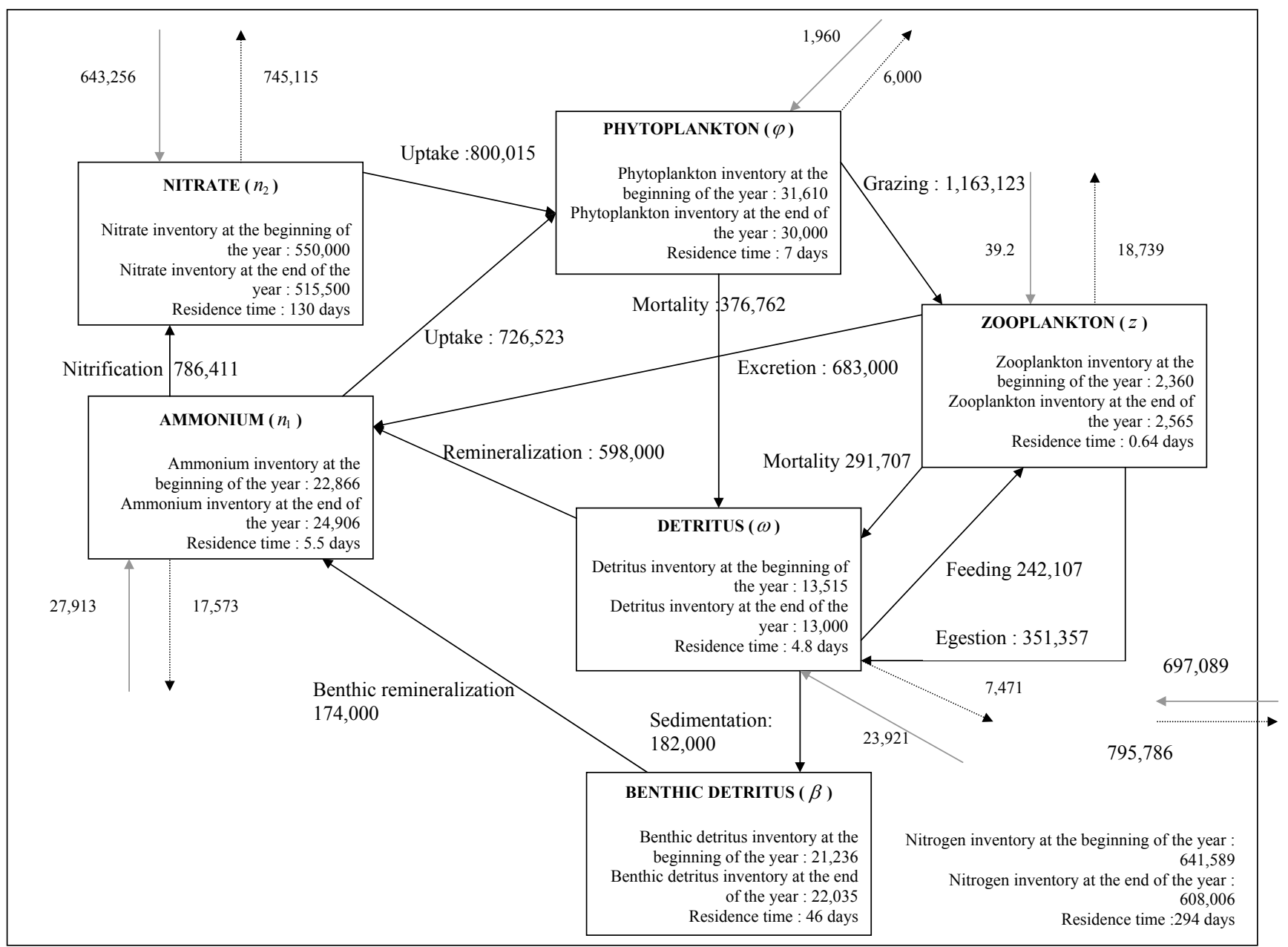

Fig. 13. Quantification of the biogeochemical interaction terms as well as the river input and the export at the shelf break for each biogeochemical state variable (annual mean values obtained after five years of integration of the model expressed in $\mathrm{t} \mathrm{N} \mathrm{yr}^{-1}$ for the north-western shelf). The evolution of the nitrogen content of each compartment after one year of integration is indicated in each box as well as its residence time (computed as the time necessary for the whole content of the box being replace by physical and biogeochemical fluxes). The arrows in dotted line represent the exchanges at the shelf break while the arrows in grey represent the rivers discharges. The nitrogen budget of the shelf waters is essentially determined by the nitrate budget.

from measured SCOC, benthic nutrient regeneration and nutrient burial in the sediment gives a POC flux to the sediments of 3.7 to $4.2 \times 10^{6} \mathrm{t} \mathrm{C} \mathrm{yr}^{-1}$ for the whole shelf which is in agreement with the value of $3.7 \times 10^{6} \mathrm{t} \mathrm{C} \mathrm{yr}^{-1}$ derived from the SCOC rates measurements (Wijsman, 2001). With this estimation, the fraction of the primary production deposited on the shelf is around 33\%, and is in agreement with the global estimation of 27 to $30 \%$ given by Wollast (1998) using in situ observations and semi-empirical equations. Also, the model estimated carbon flux to the sediment of $1.4 \times 10^{6} \mathrm{tC} \mathrm{yr}^{-1}$ is much lower than the estimate of 3.7 to $4.2 \times 10^{6} \mathrm{t} \mathrm{C} \mathrm{yr}^{-1}$ derived from in situ observations performed during EROS-21. However, it should be noted that these global fluxes derived from EROS-21 observations may have been overestimated because they are derived from mea- surements taken essentially in the most productive part of the Black Seas northwestern shelf during August and May when mineralization rates are usually high. Moreover, more than $21 \%$ of the SCOC is consumed by the activity of benthic organisms (Wijsman et al., 1999). Also, the EROS-21derived integrated values have to be considered as upper estimates. On the other hand, the coarse resolution of the shelf bathymetry used in the model (the water depth of the shelf is overestimated in the model, the lowest depth is $80 \mathrm{~m}$, while in reality, the mean shelf depth is about $50 \mathrm{~m}$ ) leads to an underestimation of the flux reaching the sediments. In the model, most of the organic matter is remineralized in the water column before reaching the bottom. The comparison of the flux of PON and ammonium respectively to and from the sediments obtained by the model and in-situ observations 


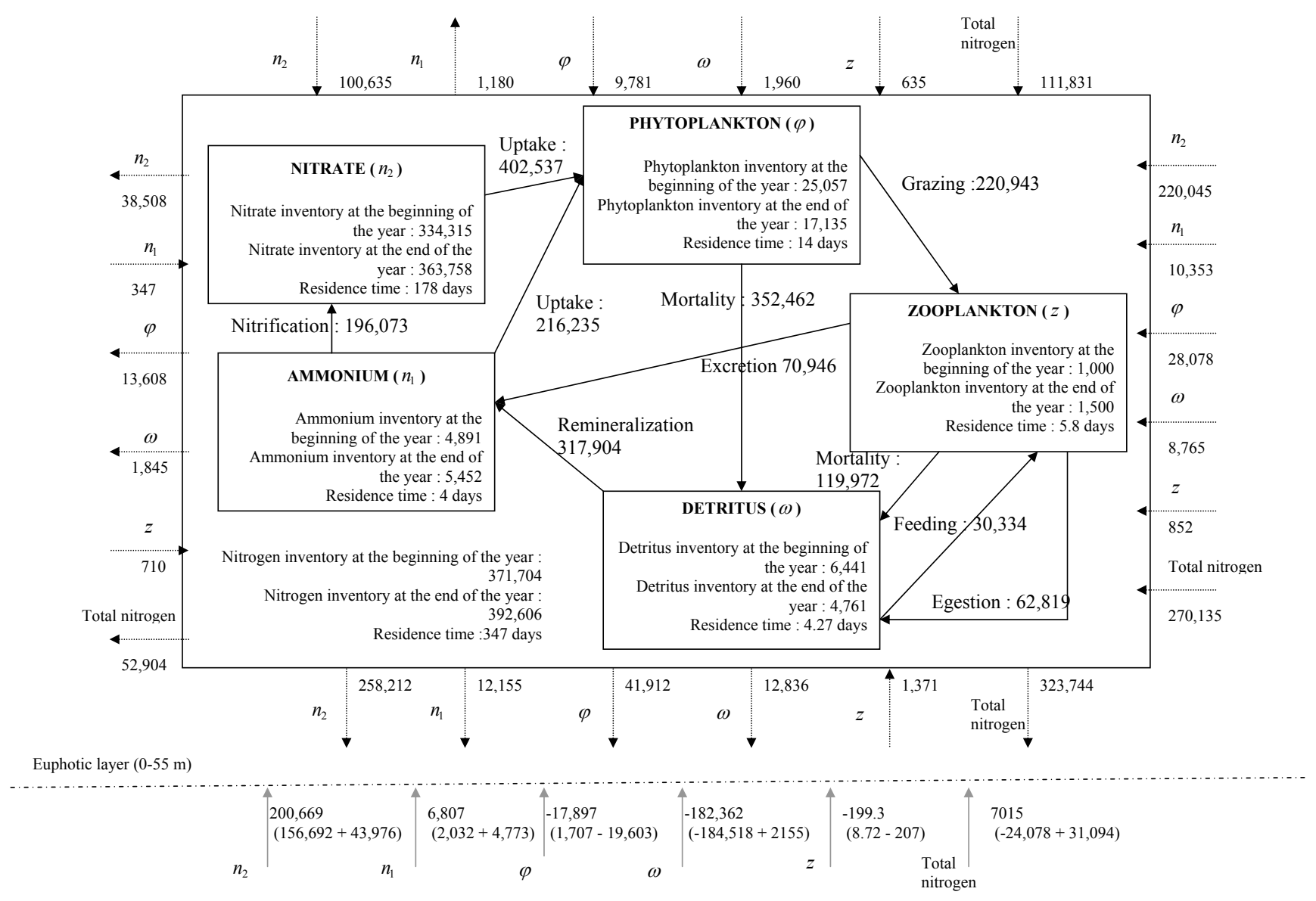

Fig. 14. Quantification of the biogeochemical interaction terms as well as the advection/diffusion horizontal/vertical fluxes associated to each biogeochemical state variable (annual mean values obtained after five years of integration of the model, expressed in $\mathrm{t} \mathrm{N} \mathrm{yr}^{-1}$ for the euphotic layer of the central basin). The evolution of the nitrogen content of each compartment after one year of integration is indicated in each box as well as its residence time (computed as the time necessary for the whole content of the box being replace by physical and biogeochemical fluxes). The arrows in dotted line represent the horizontal advection/diffusion fluxes associated to each component (horizontal arrows: meridional fluxes, vertical arrows: zonal fluxes) while the arrows in grey represent the vertical flux (the first digit in brackets is the vertical advective flux and the second one, the diffusive vertical flux).

collected during the EU EROS-21 and INTAS project is described in extenso in Gregoire and Friedrich (2004).

\subsection{Nitrogen cycling in the central basin}

\subsubsection{Nitrogen budget of the euphotic layer of the central} basin

The nitrogen budget of the euphotic layer of the central basin ( volume $=6 \times 10^{3} \mathrm{~km}^{3}$, surface $=110 \times 10^{3} \mathrm{~km}^{2}$ ) has been computed to provide the intercompartmental transfer rates and the fluxes across the base of the euphotic layer (Fig. 14). Since the denitrification process does not occur in the euphotic layer, a perfect steady state solution implies an approximate balance between the external input of total nitrogen into the euphotic layer by horizontal and vertical physical fluxes. However, this balance is not strictly verified (the annual net vertical nitrogen flux at the base of the euphotic layer is an upward flux of $7 \times 10^{3} \mathrm{t}$ and the net horizontal flux represents also a gain of nitrogen for the central basin with a value of $5 \times 10^{3} \mathrm{t}$ ) and therefore, the nitrogen content of the euphotic layer increases by $21 \times 10^{3} \mathrm{t}$ after one year of integration. This unbalance can also be explained by the existence of a possible error made when computing the net horizontal/vertical physical fluxes through the boundaries of the domain of integration since these fluxes are characterized by a pronounced spatial variability. Indeed, their standard deviation is comparable or by one order of magnitude higher than their spatial mean. It implies a strong sensitivity of the results to the size of the domain of integration. This pronounced variability can be explain by the high variability of the circulation between the coast and the main cyclonic gyres of the central basin and also around the shelf break. On the other hand, the annual nitrogen budget of each compartment 
(a)

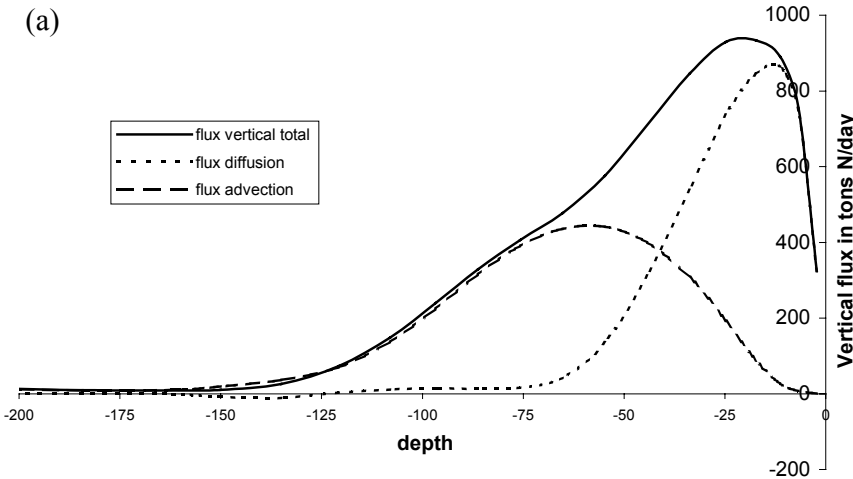

(b)

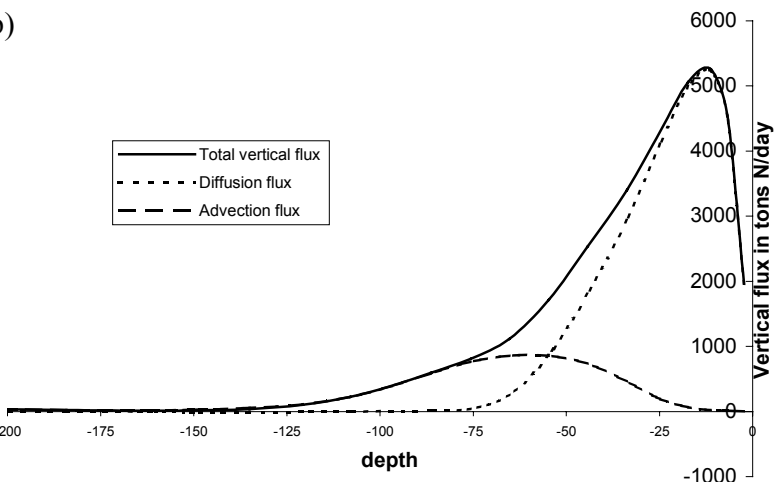

(c)

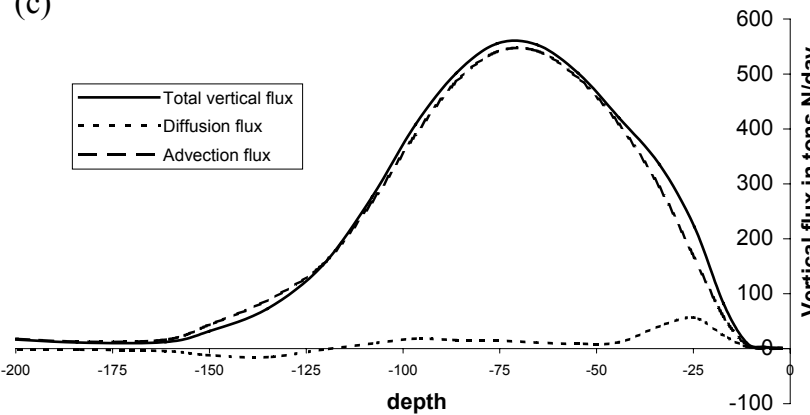

(d)

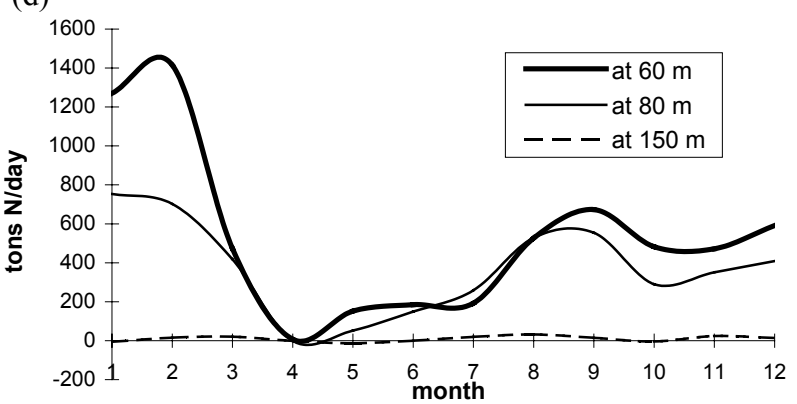

Fig. 15. Inorganic nutrients (ammonium and nitrate) vertical profile (mean values for the central basin, in $\mathrm{t} \mathrm{N} \mathrm{d}^{-1}$, positive upward): (a) annual mean vertical profile, (b) vertical profile in February, (c) vertical profile in August, (d) seasonal variations at different depth. In winter, the vertical flux is at maximum and is dominated by the vertical mixing flux whose vertical profile follows the mixing length. However, the vertical mixing does not penetrate below $75 \mathrm{~m}$ and the advective flux dominates below this depth.

is almost satisfied with an estimated relative error of less than $10 \%$ on the different physical/biogeochemical fluxes.

The vertical and horizontal physical fluxes of each biogeochemical compartment are about of the same order of magnitude except for the detritus for which the vertical flux is about 20 times higher due to the sedimentation process. However, the horizontal fluxes of each compartment roughly compensate and, when computing the budget of each biogeochemical compartment, the vertical flux of nitrate, ammonium and detritus is by about one order of magnitude higher than the net horizontal flux. The biogeochemical interaction terms are by one order of magnitude higher than the physical terms except for the detritus and nitrate. The low ratio of the nitrogen stock of each biological compartment to the biogeochemical/physical (vertical/horizontal advection/diffusion) in/outflux means that the residence time (the time necessary for the biological and physical fluxes to replace the whole stock of nitrogen of the euphotic layer) of the nitrogen content of these compartments in the euphotic layer is fairly short (from about half a year for the nitrate to a few days for the other compartments).

The nitrate and ammonium uptakes are respectively $402 \times 10^{3} \mathrm{t} \mathrm{Nyr}^{-1}$ and $216 \times 10^{3} \mathrm{t} \mathrm{N} \mathrm{yr}^{-1}$ which accounts $65 \%$ and $35 \%$ of the total annual primary production $\left(619 \times 10^{3} \mathrm{t} \mathrm{N} \mathrm{yr}^{-1}\right)$. This production is compensated by the ammonium regenerated within the euphotic zone through the remineralization of detritus $\left(318 \times 10^{3} \mathrm{t} \mathrm{N} \mathrm{yr}^{-1}\right)$ and zooplankton excretion $\left(71 \times 10^{3} \mathrm{t} \mathrm{N} \mathrm{yr}^{-1}\right)$ plus the external input of total inorganic nitrogen into the euphotic zone by horizontal and vertical advection/diffusion (respectively $24 \times 10^{3} \mathrm{t} \mathrm{N} \mathrm{yr}^{-1}$ and $207 \times 10^{3} \mathrm{t} \mathrm{N} \mathrm{yr}^{-1}$ ). These last values stress the efficiency of the in-situ regeneration process which provides over the year to the euphotic layer $389 \times 10^{3} \mathrm{t}$ of inorganic nitrogen against $231 \times 10^{3} \mathrm{t}$ for the physical processes. These values suggest also that the recycled production primarily occurs through the detrital pool rather than immediate zooplankton excretion. However, this can also result from the weak zooplankton development in the central basin due to the existence in the grazing function used in the model of a threshold concentration (i.e. $0.6 \mathrm{mmol} \mathrm{N} \mathrm{m}^{-3}$ ) below which the zooplankton does not develop (see the model description in the Appendix 1). This threshold takes into account a well-known behavior of the zooplankton which consists of stopping its feeding activity when the energy gained from the feeding of its preys is lower than the energy spent for capturing them (e.g. Mullin, 1963; Andersen and Nival, 1988). 
3.7.2 Vertical flux of inorganic nitrogen: seasonal evolution and vertical profile

The annual mean vertical profile of the total vertical flux (i.e. advection+diffusion) of inorganic nutrients (i.e. nitrate+ammonium) computed for the central basin reveals that this flux is always directed upward throughout the water column with a maximum in the euphotic zone and becomes equal to zero at $\sigma_{t}=17$ which corresponds to the beginning of the anoxic layer (Fig. 15a). In the surface layer, this flux is mainly driven by the diffusion while below the advection dominates. Throughout the year, the form of the vertical profile of the advective flux remains almost unchanged (Figs. 15a, b and c). It reveals a broad maximum at the depth of the core of the main pycnocline $\left(\sigma_{t}=15\right)$ where the vertical velocity is the highest, with a maximum of about $900 \mathrm{t} \mathrm{N} \mathrm{d}^{-1}$ in February and a minimum value of $150 \mathrm{t} \mathrm{N} \mathrm{d}^{-1}$ in May. Conversely, the profile of the diffusive flux exhibits a strong seasonal variability associated with the variability of the vertical mixing which is imprinted to the vertical profile of the total vertical flux. It mimics the profile of the mixing length with a maximum value of $5 \times 10^{3} \mathrm{t} \mathrm{N} \mathrm{d}^{-1}$ reached at $20 \mathrm{~m}$ in winter and a sharp decrease at the end of spring and in summer with values of respectively $125 \mathrm{t} \mathrm{N} \mathrm{d}^{-1}$ and $50 \mathrm{t} \mathrm{N} \mathrm{d}^{-1}$ at the base of the seasonal thermocline. Also, in the upper $100 \mathrm{~m}$ of the water column, the total vertical flux reaches its maximum in winter (February). It decreases sharply at the end of spring and in summer and increases again in fall due to the intensification of the water mixing (Fig. 15d). Konovalov et al. (2000) estimated the nitrate upward flux into the upper $80 \mathrm{~m}$ of the water column to about $2 \times 10^{10} \mathrm{~mole} \mathrm{~N} \mathrm{yr}^{-1}=767 \mathrm{t} \mathrm{N} \mathrm{d}^{-1}$ which is in the range of the model estimations.

\subsubsection{Vertical fluxes of Particulate Organic Nitrogen (PON)} and Particulate Organic Carbon (POC): vertical profile and seasonal evolution

The model estimates to about $20010^{3} \mathrm{tN} \mathrm{yr}^{-1}$ the amount of PON (living and dead) leaving the euphotic layer which represents about $33 \%$ of the primary production of the euphotic layer of the central basin. This last value is in good agreement with sediment trap observations which estimate to about $75 \%$ the part of the primary production which is remineralized in the euphotic layer. The mean $\mathrm{C}: \mathrm{N}$ atomic ratio of the rapidly sinking particulate materials is 14.1 , a value that is substantially greater than the mean $\mathrm{C}: \mathrm{N}$ atomic ratio of the suspended particulate matter (Karl and Knauer, 1991). Using this ratio, the model estimated POC flux represents a downward flux of POC of $2,394 \times 10^{3} \mathrm{tC} \mathrm{yr}^{-1}$. The residence time of the organic matter of the euphotic layer of the central basin is estimated to 17 days which is in agreement with the estimations of 13 days made by Karl and Knauer (1991).

During the whole year, the vertical flux of PON is maximal in the surface layer at $25-30 \mathrm{~m}$ with a annual downward flux of $385 \times 10^{3} \mathrm{t} \mathrm{Nyr}^{-1}$ and then decreases sharply below by more than a factor of three within the $60-80 \mathrm{~m}$ depth interval to $80 \times 10^{3} \mathrm{t} \mathrm{N} \mathrm{yr}^{-1}$ at $80 \mathrm{~m}$ for being very small at $150 \mathrm{~m}$ depth $\left(18 \times 10^{3} \mathrm{t} \mathrm{Nyr}^{-1}\right)$ (Fig. 16a). These results suggest an efficient and rapid recycling of particulate organic matter in the oxygenated layer of the water column. In agreement with sediment trap measurements (e.g. Deuser, 1971; Karl and Knauer, 1991; Lein and Ivanov, 1991; Konovalov and Murray, 2001), more than $95 \%$ of the particulate organic nitrogen produced in the euphotic layer is recycled in the upper $100 \mathrm{~m}$ of the water column, about $87 \%$ in the upper $80 \mathrm{~m}$ and $67 \%$ in the euphotic layer. In late fall and winter, the vertical flux is at maximum (about $5 \times 10^{3} \mathrm{t} \mathrm{N} \mathrm{d}^{-1}$ in February at $15 \mathrm{~m}$ ) and is dominated by the turbulent mixing, while during the rest of the year, the advection flux dominates and is at maximum in April-May at $25-30 \mathrm{~m}$ after the winter-early spring phytoplankton bloom (Fig. 16b). At this period, the vertical profiles of the PON and POC downward fluxes estimated from the model show that they vary from $23 \mathrm{mg} \mathrm{N} \mathrm{m}^{-2} \mathrm{~d}^{-1}$ and $276 \mathrm{mg} \mathrm{C} \mathrm{m}^{-2} \mathrm{~d}^{-1}$ at $54 \mathrm{~m}$, to $12.9 \mathrm{mg} \mathrm{N} \mathrm{m}^{-2} \mathrm{~d}^{-1}$ and $154 \mathrm{mg} \mathrm{Cm}^{-2} \mathrm{~d}^{-1}$ at $80 \mathrm{~m}$ and reach $1.41 \mathrm{mg} \mathrm{N} \mathrm{m}^{-2} \mathrm{~d}^{-1}$ and $16.9 \mathrm{mg} \mathrm{C} \mathrm{m}^{-2} \mathrm{~d}^{-1}$ at $150 \mathrm{~m}$. These last values agree satisfactorily with sediment trap measurements made at two stations of the central basin during May 1988 (Karl and Knauer, 1991) which revealed that the PON and POC fluxes from the base of the euphotic zone were $11.6 \mathrm{mg} \mathrm{N} \mathrm{m}^{-2} \mathrm{~d}^{-1}$ and $140 \mathrm{mg} \mathrm{C} \mathrm{m}^{-2} \mathrm{~d}^{-1}$. Beneath $60 \mathrm{~m}, \mathrm{PON}$ and POC fluxes decreased rapidly with depth to $3.3 \mathrm{mg} \mathrm{N} \mathrm{m}^{-2} \mathrm{~d}^{-1}$ and $39 \mathrm{mg} \mathrm{C} \mathrm{m}^{-2} \mathrm{~d}^{-1}$ at $80 \mathrm{~m}$, followed by a more gradual decline to $1.76 \mathrm{mg} \mathrm{N} \mathrm{m}^{-2} \mathrm{~d}^{-1}$ and $21.5 \mathrm{mg} \mathrm{C} \mathrm{m}^{-2} \mathrm{~d}^{-1}$ at $175 \mathrm{~m}$.

This relatively high mid-water POC and PON fluxes indicate that even in the less productive area of the basin, the particle flux to the deep waters is significant. These fluxes of POC and PON lost towards the deep waters are nearly indistinguishable from the open ocean particle fluxes measured in oxygenated environments $\left(17.2 \mathrm{mg} \mathrm{C} \mathrm{m}^{-2} \mathrm{~d}^{-1}\right.$ for "open ocean composite" profiles, Martin et al., 1987 vs. $16.9 \mathrm{mg} \mathrm{C} \mathrm{m}^{-2} \mathrm{~d}^{-1}$ for the Black Sea). However, according to Karl and Knauer (1991), the attrition of sinking particles with increasing water depth in the Black Sea is minimal compared to oxygenated oceanic habitats and thus, this flux to the deep Black Sea waters $(>2000 \mathrm{~m}$ ) would be expected to exceed that measured for the Pacific Ocean by nearly two orders of magnitude. Also, this elevated downward flux of POM from the surface waters of the Black Sea is an important process which is necessary to maintain the present day anoxic conditions of this enclosed marine area (Karl and Knauer, 1991).

\subsection{Export of carbon towards the anoxic layer}

The export of carbon towards the anoxic layer essentially depends on the amount of organic matter produced in the euphotic layer by the biological production or brought by the 


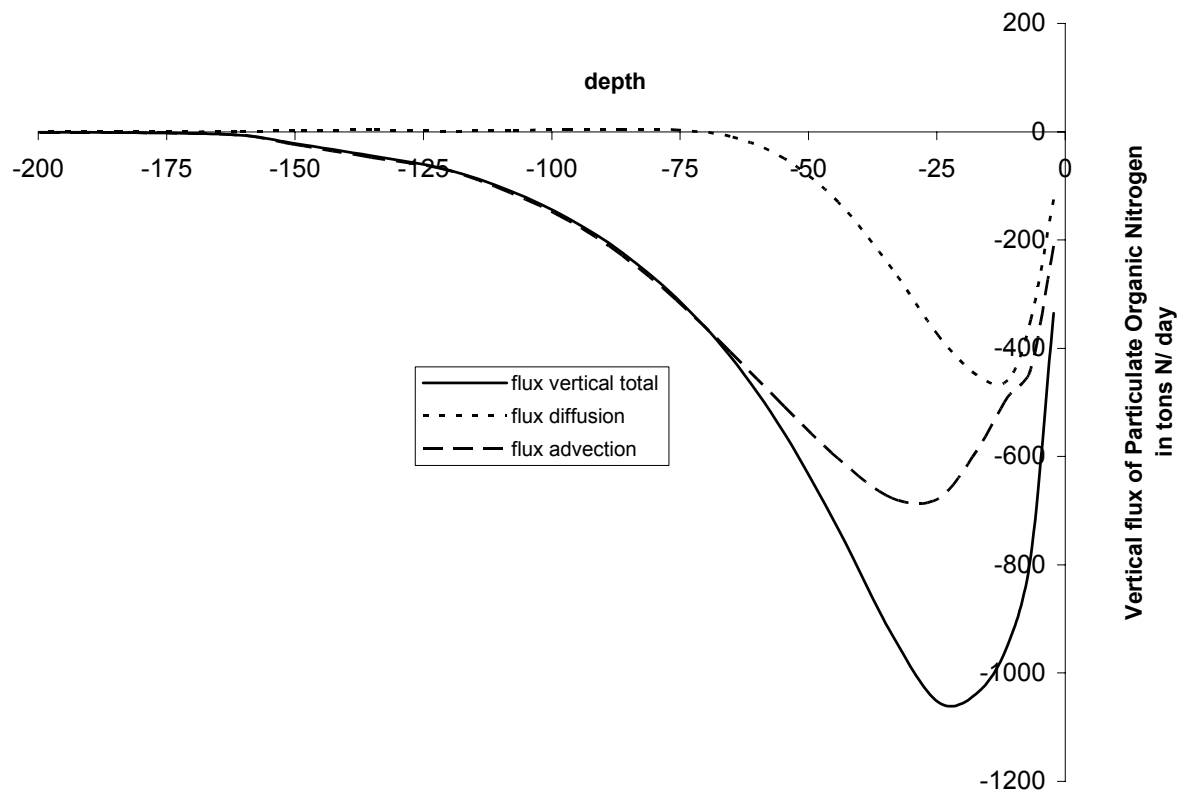

(a)

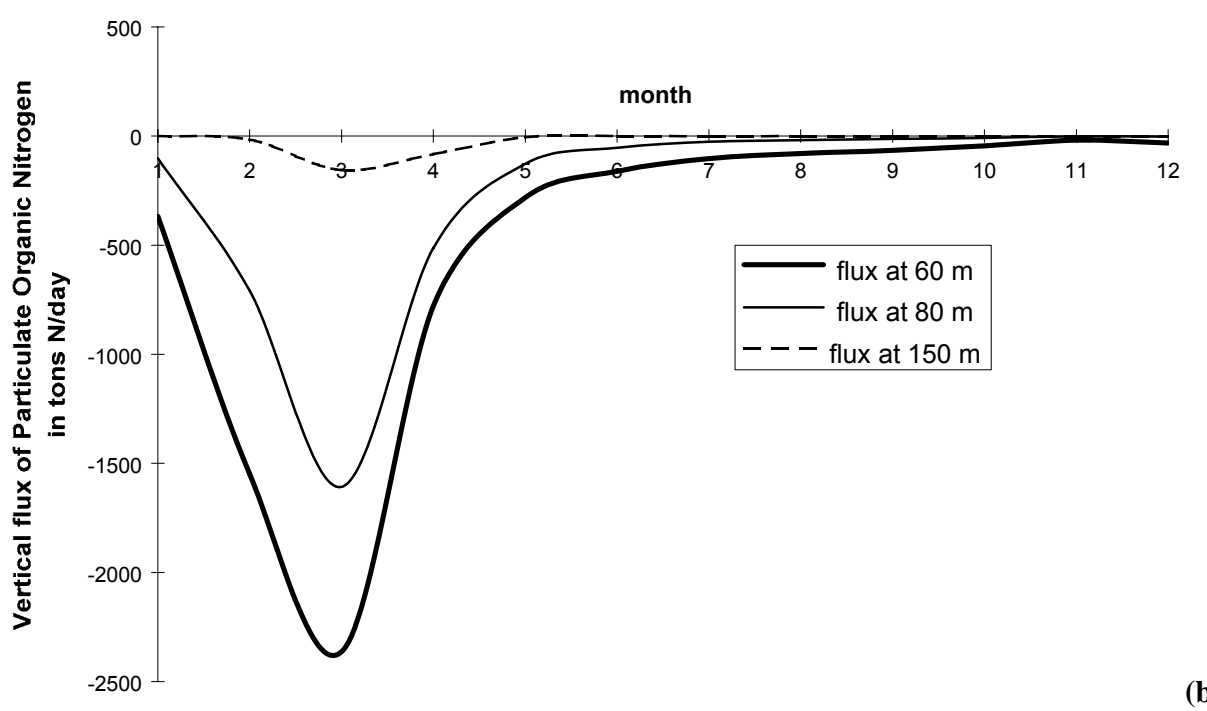

Fig. 16. Vertical flux of Particulate Organic Nitrogen (mean values for the central basin, in $\mathrm{t} \mathrm{N} \mathrm{d} \mathrm{d}^{-1}$, negative values=downward flux): (a) annual mean vertical profile, (b) seasonal variations at selected depths.

rivers. The model estimates the annual loss of particulate organic nitrogen $(\mathrm{PON})$ towards the anoxic layer to $40 \times 10^{3} \mathrm{t}$. Using the $\mathrm{C}: \mathrm{N}$ atomic ratio of 14 observed for the particulate organic matter by Karl and Knauer (1991), the annual loss of POC towards the anoxic layer equals $4.610^{10} \mathrm{~mol} \mathrm{yr}^{-1}$. This last value is in the lower range of the observed estimates of $6 \times 10^{10}-2 \times 10^{11} \mathrm{~mol} \mathrm{yr}^{-1}$ (Muramoto et al., 1991), $2.5 \times 10^{11} \mathrm{~mol} \mathrm{yr}^{-1}$ (Deuser, 1971), 3.6 $\times 10^{11} \mathrm{~mol} \mathrm{yr}^{-1}$ (Karl and Knauer, 1991) and 5-40 $\mathrm{mg} \mathrm{C} \mathrm{m}^{-2} \mathrm{~d}^{-1}$ (Honjo et al., 1987). However, it should be noted that these last estimates are obtained by integrating over the 3D space and the time some sediment trap measurements conducted in different areas of the deep basin at different period corresponding usually to post bloom events (e.g. Karl and Knauer, 1991). Therefore, it is impossible to know whether their space-time resolution is high enough for their values being representative of the whole basin. The model estimated loss of POC towards the anoxic zone represents $2 \%$ of the open sea (defined as the region outside the north-western shelf) integrated primary production which is in a good agreement with the estimate of 3\% obtained from observations (Karl and Knauer, 1991). 


\section{Discussion}

In order to get a better understanding of the biogeochemical functioning of the Black Sea on a seasonal and annual scale, a 3D coupled biogeochemical model has been developed. Although the ecosystem model used in this study is a rather simplistic model with somewhat crude parameterization of some processes, the simulations show that the model is capable of reproducing the basic features of the plankton and nutrients dynamics in the Black Sea and helps in understanding and interpreting the available observations. However, the quantitative comparison of model results with satellite and field observations reveals that the model underestimates the phytoplankton bloom and the level of primary production, especially in regions of extremely high nutrients concentrations, such as the Danube's discharge area and the western coast, where the phytoplankton grows at almost nutrients saturation conditions. This deficiency of the model has already been discussed in Grégoire et al. (2004) and it was concluded that a more complex ecosystem model involving notably an explicit representation of higher predators seems to be necessary to obtain a more accurate description of the present day Black Sea's ecosystem characteristics strongly affected by eutrophication.

The model simulations were nevertheless used for diagnostic purposes.

Four main sources of errors have been identified when computing the nitrogen fluxes produced by the model:

1. an error on the computation of the biogeochemical interaction terms which results from the fact that the numerical scheme used to discretize these terms is not perfectly conservative. This error is easily controllable by reducing the time step of integration. Also, using a time step of one hour to integrate the biogeochemical equations, the relative error on the interaction terms does not exceed $2-3 \%$.

2. An error on the diagnostic computation of the water and nitrogen export at the shelf break. This error results from the interpolation of the advection/diffusion horizontal fluxes on a grid different from the numerical grid of the model. The relative error on the export is estimated to $6-8 \%$.

3. An error on the computation of the transport of biogeochemical constituents by vertical/horizontal advection/diffusion physical processes integrated over the lateral and lower boundaries of the euphotic layer of the central basin. This error can be explained by the high spatial variability of these fluxes and, thus, their high sensitivity to the size of the domain of integration. To estimate this error, we have computed the annual budget over the euphotic layer of the central basin of a passive tracer. Also, the relative error on the integrated verti- cal/horizontal advection/diffusion fluxes has been estimated to $8-10 \%$.

4. An error on the data used to initialize and especially to force the model at its open boundaries. For instance, in the literature, the annual load of inorganic nitrogen brought by the Danube varies between $600 \times 10^{3} \mathrm{t}$ to $1000 \times 10^{3}$ t (e.g. Sur et al., 1994; Cociasu et al., 1997; Humborg et al., 1997; Konovalov et al., 2000; Friedrich et al., 2002).

Therefore, the estimated error made on the fluxes computed by the model is totally acceptable considering the order of magnitude of the error on the boundary conditions used to force the model which constitutes the dominant source of error.

The comparison of the nitrogen cycle of the shelf and of the euphotic layer of the central basin shows that, for almost similar volumes $\left(6 \times 10^{3} \mathrm{~km}^{3}\right.$ for the central basin and $4.7 \times 10^{3} \mathrm{~km}^{3}$ for the shelf), the biogeochemical fluxes of the shelf are in the mean by 2 to 3 times higher than in the central basin and the primary production of the euphotic layer of the central basin represents about $40 \%$ of the primary production of the north-western shelf. The process of in-situ regeneration through detritus remineralization and zooplankton excretion is particularly efficient on the shelf as well as in the central basin providing a annual higher stock of inorganic nutrients that the river inputs (for the shelf) and the physical processes (for the central basin). The primary production of the shelf waters is fuelled by the rapid recycling of nutrients, the rivers discharges and nitrate inputs from the deep sea at the shelf break; while, in the central basin, the primary production relies essentially on nutrients being entrained from below. In both regions, the ratios of the nitrogen content of the biogeochemical compartments on the different physical/biological fluxes are low and roughly comparable. This results in similar residence times and this indicates that small changes in the physical/biogeochemical fluxes could result in substantial changes in these compartments on very short time scales.

It was found that the shelf acts throughout the year as a nutrient source for the deep sea. The input of nitrogen by the rivers roughly corresponds to the export towards the open sea at the shelf break. Indeed, the huge amount of inorganic nitrogen introduced every year by the rivers or produced in-situ by the regeneration process is not entirely consumed on the shelf and about $36 \%$ is exported towards the deep sea. At the shelf break, the space-time variability of the nitrogen and water export is extremely high due to the 3D complexity of the circulation in the region. The nitrogen export towards the deep sea is mainly concentrated in the first upper $55 \mathrm{~m}$ (with an annual nitrogen export of $610 \times 10^{3} \mathrm{t}$ ). Also, the annual input of inorganic nitrogen to the euphotic layer of the open sea from the shelf (i.e. $585 \times 10^{3}$ t) is comparable to the input into the euphotic layer from the oxycline by vertical advection/diffusion (i.e. $440 \times 10^{3}$ t). 
It should be noted that the capacity of the shelf to act as a sink/source of nutrients for the deep sea is directly linked to the sediment processes and, in particular, to the capacity of the sediments to eliminate nitrogen or to bury nitrogen. However, at this stage, sediments are roughly parameterized in the model. For instance, some important benthic processes of nitrogen elimination such as denitrification are not represented although, this last process has been found to be an important remineralization pathway especially in summer with denitrification rates in the range of a few mmol N m${ }^{-2} \mathrm{~d}^{-1}$ (Gregoire and Friedrich, 2004). In the model, almost all the organic matter reaching the sediments is rapidly remineralized and reinjected in the water column through a benthic ammonia flux.

The denitrification process occurring in waters deficient in oxygen has been found a quiet effective process of nitrogen elimination from the Black Sea environment providing its ability to resist to the dramatic eutrophication process over the last 20 years. Recent literature estimates of the free nitrogen production in the open ocean range from $12 \times 10^{7} \mathrm{t} \mathrm{N} \mathrm{yr}^{-1}$ (Codispoti and Christensen, 1985) to $25 \times 10^{7} \mathrm{t} \mathrm{Nyr}^{-1}$ (Devol, 1991) and consists generally of three sources: the eastern tropical North Pacific, the eastern tropical South Pacific and the Arabian Sea (Yakushev and Neretin, 1997). The total input of the Black Sea to the global oceanic free nitrogen production is therefore small (less than $0.5 \%$ ) compared with other regions with similar oxygendeficient conditions. For instance, estimates of free nitrogen production in the Arabian Sea range from $12 \times 10^{6} \mathrm{t} \mathrm{N} \mathrm{yr}^{-1}$ (Mantoura et al., 1993) to $34 \times 10^{6} \mathrm{t} \mathrm{N} \mathrm{yr}^{-1}$ (Yakushev and Neretin, 1997), nearly 10-30\% of the whole ocean denitrification production. This difference can be explained by the small volume of the Black Sea's waters affected by denitrification. Indeed, in the Black Sea, the upper boundary of active nitrate-reduction is limited by the oxygen content and the lower boundary is limited by the nitrate content. Also, nitrate reduction in the Black Sea is concentrated in a layer $90-110 \mathrm{~m}$ deep with a surface of about $0.3 \times 10^{5} \mathrm{~km}^{2}$, while, in the Arabian Sea, the area of denitrification is located between 450 and $650 \mathrm{~m}$ and extends on $1.37 \times 10^{6} \mathrm{~km}^{2}$.

\section{Conclusions}

A 3D coupled hydrodynamical-biogeochemical model has been applied in the Black Sea at basin scale to simulate the seasonal cycle of the ecohydrodynamics. After 5 years of integration of the coupled model, almost repetitive yearly cycles of the biological variables are reached and the results of the quasi-steady state solution have been diagnosed in order to quantify global nitrogen fluxes (integrated in space and over the year). In particular, the exchanges of water and nutrients between the shelf and the deep sea, the export of organic matter towards the shelf sediments and the anoxic deep waters of the open sea, the Black sea production of nitrogen gas due to denitrification and the vertical fluxes of nutrients at the base of the euphotic layer of the central basin were estimated and their seasonal variations were analyzed and explained in terms of the variability of the ecohydrodynamics. The errors associated to the non-perfect conservativity of the numerical scheme and to the space and time integration of these highly variable biogeochemical fluxes have been quantified and found acceptable regarding the unavoidable margins of error that we have on the data used to force the model at the open sea boundaries (i.e. the rivers, the Bosporus Strait, the atmosphere). Both on the shelf and in the upper layer of the deep sea, it has been found that the ratios of the nitrogen content of the biogeochemical compartments on the different physical/biological fluxes are low and roughly comparable. This results in similar residence times and this indicates that small changes in the physical/biogeochemical fluxes could result in substantial changes in these compartments on very short time scales. The model shows that $67 \%$ $\left(4.5 \times 10^{5} \mathrm{t} \mathrm{N} \mathrm{yr}^{-1}\right)$ of the total annual load of inorganic nitrogen brought into the shelf by the rivers is irreversibly lost each year by the denitrification process occurring in the suboxic layer. It has been found that the shelf acts throughout the year as a nutrient source for the deep sea. The input of nitrogen by the rivers roughly corresponds to the net nitrogen export towards the open sea at the shelf break. The input of nitrate from the open sea to the shelf is roughly equivalent to the river nitrate discharge on the shelf but is only half the total export towards the deep sea. This net export of nitrate towards the deep sea is roughly equivalent to the nitrate input into the euphotic layer of the deep sea from the oxycline by vertical physical processes. However, this high export of nitrate from the shelf to the deep sea may have been overestimated because the model does not consider the possibility of nitrogen elimination on the shelf by benthic denitrification and burial.

Also, further development of our model will include the complexification of the foodweb representation by adding higher predators and by considering several size classes of plankton and also the coupling of the existing model with a regional early diagenetic model in order to obtain an explicit description of the anaerobic mineralization (manganese reduction, iron reduction, sulfide reduction and methanogenesis) and re-oxidation processes (Soetaert et al., 1996).

\section{Appendix 1}

The evolution in space and time of the 3D biogeochemical state variables (except $\beta_{n}$ ) is described by equations of the general following form:

$$
\frac{\partial y}{\partial t}+\nabla_{H} \cdot(\boldsymbol{u} y)+\frac{\partial w y}{\partial z}+\frac{\partial\left(w_{y}^{s} y\right)}{\partial z}=Q^{y}+\frac{\partial}{\partial z}\left(\tilde{\lambda}^{y} \frac{\partial y}{\partial z}\right)+\lambda_{H} \nabla_{H}^{2} y
$$


Notation:

$y$ : any $3 \mathrm{D}$ biogeochemical state variable.

$t$ : the time.

$z$ : the vertical coordinate.

$\partial$ : partial differentiation.

$\nabla_{H}$ : the horizontal differential operator.

$\boldsymbol{u}$ : the horizontal velocity.

$w$ : the vertical velocity.

$\tilde{\lambda}^{y}$ : the vertical turbulent diffusivity coefficient.

$\lambda_{H}$ : the horizontal diffusion coefficient.

$Q^{y}$ : the local production-destruction term resulting from

biogeochemical interactions

$w_{y}^{s}$ : the sedimentation velocity (only for detritus).

This equation illustrates the different ways according to which the hydrodynamics influences the ecodynamics. In particular, the transport of any biogeochemical state variable results from the superposition of a global entrainment by the mean flow (i.e. horizontal and vertical advection: $\left.\nabla_{H} \cdot(\boldsymbol{u} y)+\frac{\partial w y}{\partial z}\right)$ and of a slipping through the flow due to the diffusion of $y$ (i.e. horizontal and vertical diffusion: $\left.\lambda_{H} \nabla_{H}^{2} y+\frac{\partial}{\partial z}\left(\tilde{\lambda}^{y} \frac{\partial y}{\partial z}\right)\right)$ or to its migration (i.e. $\left.\frac{\partial\left(w_{y}^{s} y\right)}{\partial z}\right)$. The detritus migration velocity, $w_{\omega}^{s}$, is expressed as a function of the detritus concentration to take into account that at high concentrations, detritus can form aggregate and this aggregation speeds up the sedimentation (e.g. Totterdell et al., 1993; Oguz et al., 1998). The mathematical expression of $Q^{y}$ is given in Fig. 2. The mathematical formulation of the biogeochemical processes is given in Table 1 and the parameters used are listed in Table 2.

\section{Phytoplankton}

The major biogeochemical fluxes governing the phytoplankton evolution (see the different terms of $Q^{\varphi}$ in Fig. 2) are nutrient uptake (see Eq. 4 in Table 1), lysis (see (10) in Table 1) and grazing by heterotrophs (see Eq. 14 in Table 1). The total primary production, $F_{n_{1}, n_{2}}^{\varphi}$, (see Eq. 1 in Table 1 ) is expressed as the product between the photosynthetic rate $L_{\varphi}(I)$ (see Eq. 5 in Table 1), described by the mathematical formulation of Platt and Jassby (1976), and the nutrient uptake function, $N_{\varphi}\left(n_{1}, n_{2}\right)$, represented by the classical Michaelis-Menten-Monod kinetics (see Eq. 4 in Table 1). A $Q_{10}$ law is used to model the temperature influence on the phytoplankton development (see Eq. 3 in Table 1).

\section{Zooplankton}

For the zooplankton compartment, the fluxes involved are the grazing (see Eq. 11 in Table 1), excretion (see Eq. 18 in Table 1) and mortality (see Eq. 17 in Table 1) (see the different terms of $Q^{z}$ in Fig. 2). The zooplankton is assumed to feed on phytoplankton and detritus with different but constant capture efficiencies (see Eq. 13 in Table 1). The ingestion rate, $F_{\varphi, \omega}^{z}$, as a function of the food concentration is assumed to follow a Michaelis-Menten type relationship considering that when the prey concentration is under a given threshold the zooplankton ceases its feeding activity (e.g. Mullin, 1963; Andersen and Nival, 1988).

Pelagic Detritus

The zooplankton fecal pellets (see Eq. 16 in Table 1), constituting the unassimilated part of the ingested food, as well as the phytoplankton and zooplankton lysis (see Eqs. 10 and 17 in Table 1) are the source of detritus. Detritus are recycled in the water column as a result of ingestion by zooplankton (see Eq. 15 in Table 1) and remineralization into ammonium (see Eq. 19 in Table 1) (see the different terms of $Q^{\omega}$ in Fig. 2). They are also submitted to sedimentation.

\section{Benthic Detritus}

Benthic detritus are formed by the sedimenting particulate organic nitrogen which is deposited on the bottom (see the different terms of $Q^{\beta_{n}}$ in Fig. 2). They are recycled via benthic remineralization according to a first order law proposed by Billen and Lancelot (1988) (see Eqs. 24 and 25 in Appendix 2). As a result, ammonium is injected from the benthic compartment into the bottom layer of the water column.

\section{Ammonium}

The excretion of zooplankton (see Eq. 18 in Table 1) as well as the remineralization of detritus (see Eq. 19 in Table 1) constitute the ammonium sources. The consumption of ammonium results from its uptake by phytoplankton (see Eq. 8 in Table 1) and its oxidation into nitrate in the nitrification process occurring in aerobic waters (see Eq. 20 in Table 1) (see the different terms of $Q^{n_{1}}$ in Fig. 2).

Nitrate

The nitrification process constitutes the only source of nitrate (see Eq. 20 in Table 1). The consumption of nitrate results from its uptake by phytoplankton (see Eq. 9 in Table 1) and its reduction into nitrogen gas (i.e. the denitrification) (see Eq. 22 in Table 1) (see the different terms of $Q^{n_{2}}$ in Fig. 2).

\section{Appendix 2}

Initial conditions

The hydrodynamic model is initialized with horizontally homogeneous temperature and salinity fields presenting a vertical stratification typical of the mean climatological Black Sea state. The most important characteristics of the vertical stratification are the sharp halocline from the sea surface down to $200 \mathrm{~m}$ and the cold intermediate layer (CIL), analogous to the $18^{\circ} \mathrm{C}$ water layer in the Atlantic ocean (Stanev and Beckers, 1999). The initial vertical profiles of inorganic 
Table 1. Mathematical formulation of the biogeochemical processes.

\section{Symbol Mathematical expression of the biological processes}

$F_{n 1, n 2}^{\varphi} \quad$ Flux of nitrogen consumed by phytoplankton

$$
\begin{aligned}
& F_{n, n 2}^{\varphi}=\mu_{\varphi}\left(I, T, n_{1}, n_{2}\right) \varphi \\
& \mu_{\varphi}\left(I, T, n_{1}, n_{2}\right)=\mu_{m \varphi}\left(T=20^{\circ} C\right) \vartheta_{\varphi}(T) N_{\varphi}\left(n_{1}, n_{2}\right) L_{\varphi}(I) \\
& \vartheta_{\varphi}(T)=Q_{10}^{\frac{T-20}{10}} \\
& N_{\varphi}\left(n_{1}, n_{2}\right)=\frac{n_{1}}{c_{n 1}+n_{1}}+\frac{n_{2}}{C_{n 2}+n_{2}} \exp \left(-\psi n_{1}\right) \\
& L_{\varphi}(I)=\tanh \left[\frac{\alpha I(z)}{\mu_{m \varphi}\left(T=20^{\circ} C\right) \vartheta_{\varphi}(T)}\right] \\
& I(z)=I(z=0) \exp \left[-\int_{0}^{z} k(z) d z\right] \\
& k=k_{\text {water }}+k_{\varphi} \varphi+k_{\omega} \omega
\end{aligned}
$$

$F_{n 1}^{\varphi} \quad$ Flux of ammonium consumed by phytoplankton

$$
F_{n 1}^{\varphi}=\mu_{m \varphi}\left(T=20^{\circ} C\right) \theta_{\varphi}(T) L_{\varphi}(I) \frac{n_{1}}{C_{n 1}+n 1} \varphi
$$

$F_{n 2}^{\varphi} \quad$ Flux of nitrate consumed by phytoplankton

$$
\text { (9) } \quad F_{n 2}^{\varphi}=\mu_{m \varphi}\left(T=20^{\circ} C\right) \vartheta_{\varphi}(T) L_{\varphi}(I) \frac{n_{2}}{C_{n 2}+n_{2}} \exp (-\psi n n) \varphi
$$

$F_{\varphi}^{\omega} \quad$ Flux of phytoplankton mortality

$$
F_{\varphi}^{\omega}=\delta_{\varphi}^{\omega} \varphi
$$

$F_{\varphi, \omega}^{z}$

Flux of zooplankton ingestion

$$
\begin{aligned}
& F_{\varphi, \omega}^{z}=\delta_{\bar{\varphi}, \omega}^{z}\left(b_{z}\right) z=\left(\delta_{\bar{\varphi}, \omega}^{z}\right)_{\max } \frac{x}{c_{z}+x} U(x) z \\
& x=b_{z}(\varphi, \omega)-b_{z} \\
& b_{z}(\varphi, \omega)=e_{z} \varphi+e_{z} \omega \\
& U(x)=\text { heaviside }
\end{aligned}
$$

$F_{\bar{\varphi}}^{z}$

Flux of phytoplankton ingestion by zooplankton

$$
F_{\varphi}^{z}=\delta_{\tilde{\varphi}}^{z}\left(b_{z}, \varphi\right) z=\frac{\delta_{\varphi, \omega}^{z}\left(b_{z}\right)}{b_{z}(\varphi, \omega)} e_{z \varphi} \varphi z
$$

$F_{\omega}^{z}$

Flux of detritus ingestion by zooplankton

$$
F_{\omega}^{z}=\delta_{\tilde{\omega}}^{z}\left(b_{z}, \omega\right) z=\frac{\delta_{\varphi, \omega}^{z}\left(b_{z}\right)}{b_{z}(\varphi, \omega)} e_{z \omega} \omega z
$$

$p F_{z}^{\omega} \quad$ Flux of zooplankton egestion

$$
p F_{z}^{\omega}=\left(1-a_{z}\right) F_{\phi, \omega}^{z}
$$

$(1-p) F_{z}^{\omega} \quad$ Flux of zooplankton mortality

$$
(1-p) F_{z}^{\omega}=m_{z} z
$$

$F_{z}^{n 1} \quad$ Flux of zooplankton excretion

$$
F_{z}^{n 1}=\delta_{z}^{n} z
$$

$F_{o 1}^{m} \quad$ Flux of detritus remineralisation

$$
F_{\omega}^{n_{1}}=\delta_{\omega}^{n_{1}} \omega
$$

$F_{n 1}^{n_{2}} \quad$ Flux of nitrification

$$
F_{n_{1}}^{n_{2}}=\delta_{n_{1}}^{n_{2}} f_{n}\left(\sigma_{t}\right) n_{1}
$$

$$
f_{n}\left(\sigma_{t}\right)=f_{n}^{0} U\left(\sigma_{t 1}-\sigma_{t}\right)+\frac{g_{n}\left(\sigma_{t}\right)}{R_{n}+g_{n}\left(\sigma_{t}\right)} U\left(\sigma_{t}-\sigma_{t 1}\right) U\left(\sigma_{t 2}-\sigma_{t}\right)
$$

$$
U(x)=\text { heaviside function }
$$

$F_{n 2}^{N_{2}}$

$$
\text { Flux of denitrification }
$$

$$
\begin{aligned}
& F_{n_{2}}^{N_{2}}=\delta_{n_{2}}^{N_{2}} f_{d}\left(\sigma_{t}\right) n_{2} \\
& f_{d}\left(\sigma_{t}\right)=\frac{R_{d}}{R_{d}+g_{d}\left(\sigma_{t}\right)} U\left(\sigma_{t}-\sigma_{t 2}\right)
\end{aligned}
$$


Table 2. Signification, values and units of the parameters used in the formulation of the biological interaction terms.

Parameters

Phytoplankton

$\overline{\mu_{\mathrm{m}_{\varphi}}}\left(\mathrm{T}=20^{\circ} \mathrm{C}\right)$ Growth rate at $20^{\circ} \mathrm{C}$

$\mathrm{Q}_{10} \quad \mathrm{Q}_{10}$ factor

$\mathrm{c}_{\mathrm{n}_{1}}$

$\mathrm{c}_{\mathrm{n}_{2}}$

$\psi$

$\alpha$

$\mathrm{k}_{\omega}$

$k_{\varphi}, k_{\omega}$

$\delta_{\varphi}^{\omega}$

\section{$\underline{\text { Zooplankton }}$}

$\left(\delta_{\varphi, \omega}^{z}\right)_{\max }$

$\mathrm{a}_{\mathrm{z}}$

$\mathrm{c}_{\mathrm{z}}$

$b_{0 z}$

$\mathrm{e}_{\mathrm{z \varphi}}$

$\mathrm{e}_{z \omega}$

$\delta_{\mathrm{z}}^{\mathrm{n}_{1}}$

$\mathrm{m}_{\mathrm{z}}$

Nitrification and denitrification

$\delta_{n_{1}}^{n_{2}}$

$\mathrm{R}_{\mathrm{n}}$

$\mathrm{f}_{\mathrm{n}}^{0}$

$\sigma_{t 1}$

$\sigma_{t 2}$

$\delta_{n 2}^{N_{2}}$

$\mathrm{R}_{\mathrm{d}}$

$\underline{\text { Detritus }}$

$\delta_{\omega}^{\mathrm{n}_{1}}$

$\left(w_{s}^{\omega}\right)_{\max }$

$c_{\omega}$

\section{Benthic detritus}

$\mathrm{k}_{\text {sed }}$ occur

detritus sinking rate

remineralization rate
Maximum grazing rate

Assimilation efficiency

Half saturation constant for ingestion

Threshold concentration

Capture efficiency of phytoplankton

Capture efficiency of detritus

Excretion rate

Mortality rate

$\begin{array}{cc}\text { Units } & \text { Value } \\ \text { day }^{-1} & 3 \\ - & 1.88 \\ \mathrm{mmol} \mathrm{N} \mathrm{m}^{-3} & 0.2 \\ \mathrm{mmol} \mathrm{N} \mathrm{m}^{-3} & 0.5 \\ \left(\mathrm{mmol} \mathrm{N} \mathrm{m}^{-3}\right)^{-1} & 1.46 \\ \left(\mathrm{Wm}^{-2}\right)^{-1} \text { day }^{-1} & 0.015 \\ \mathrm{~m}^{-1} & 0.08 \\ \mathrm{~m}^{-1}\left(\mathrm{mmol} \mathrm{N} \mathrm{m}^{-3}\right)^{-1} & 0.07 \\ \text { day }^{-1} & 0.05\end{array}$

day $^{-1}$

0.9

0.75

$$
\mathrm{mmol} \mathrm{N} \mathrm{m}{ }^{-3}
$$

$\mathrm{mmol} \mathrm{N} \mathrm{m}{ }^{-3}$

0.6

-

0.7

$-$

0.5

day $^{-1}$

0.1

day $^{-1}$

0.05

$$
\text { day }^{-1}
$$

$\mathrm{mmol} \mathrm{O}_{2} \mathrm{~m}^{-3}$

Half-saturation constant for the limitation function of the nitrification process by the availability of oxygen

Value of the limitation function of the nitrification process by the availability of oxygen in surface waters

Density of the oxycline upper boundary

Density above which the nitrification process ceases due to oxygen deficiency and the denitrification process starts to

Maximum denitrification rate

Constant used in the inhibition function of the denitrification rate by the presence of oxygen

$\begin{array}{cc}- & 0.87 \\ \mathrm{~kg} \mathrm{~m}^{-3} & 14.8 \\ \mathrm{~kg} \mathrm{~m}^{-3} & 15.6 \\ & \\ \text { day }^{-1} & 0.015 \\ \mathrm{mmol} \mathrm{O}_{2} \mathrm{~m}^{-3} & 2.5\end{array}$

$\begin{array}{cc}\text { day }^{-1} & 0.07 \\ \text { m day }^{-1} & 8 \\ \text { mmol N m}^{-3} & 0.2\end{array}$

Half-saturation constant used in the expression of the

Maximum detrital sinking velocity

Benthic detritus remineralization rate day $^{-1}$ 
nutrients are computed as a function of the density rather than depth so as to exclude variability resulting from dynamical effects. Spatial and temporal mean vertical profiles on a density scale reconstructed from in-situ data collected during the 1988 Knorr and 1991 Bilim research cruises throughout the Black Sea are used (profiles taken from Tugrul et al., 1992 and Saydam et al., 1993). The $\mathrm{NH}_{4}$ concentration in the deep waters is set initially to zero because, on the one hand, this ammonium does not take part in the nitrogen cycle of the oxygenated layer (e.g. Brewer and Murray, 1973; Murray et al., 1995; Yakushev and Neretin, 1997; Oguz et al., 2000) and, on the other hand, the model does not represent some important chemical reactions involving, notably, the manganese and iron cycles which prevent the ammonium of the deep basin reaching the euphotic layer. For the organic matter (living and dead), initial constant values are imposed.

\subsection{Boundary conditions}

The hydrodynamic model is forced by monthly mean climatological forcing functions. In particular, this includes the large scale free surface gradients along the Bosphorus Strait, the wind stress at the air-sea interface and the outflow of the Danube, the Dnepr and the Dnestr rivers on the north-western shelf. The wind stress curl is cyclonic during the whole year with a maximum in January and a minimum in April-May. Contrary to the wind stress curl, which has a single maximum, the wind stress magnitude reaches two maxima (in winter and summer) and two minima (in spring and fall) (Staneva and Stanev, 1999). Temperature and salinity values are relaxed towards climatological monthly mean values at the surface. Monthly mean data of Altman and Kumish (1986) are used to compute the river fresh water discharges. At the Bosphorus strait, the exchanges with the Mediterranean Sea are organized as a two-layer flow. The barotropic component of the flow is computed as a function of the difference between the sea surface level of the Black Sea computed by the model at the entrance of the strait and the mean sea surface level of the Mediterranean Sea. A linearized version of the relation proposed by Oguz et al. (1990) is used with the assumption that the Mediterranean sea level remains unchanged throughout the year. Also, the increased river discharge in spring and summer tends to increase the Black Sea's sea surface elevation and, thus, amplifies the water export towards the Mediterranean. Conversely, in fall, when the river discharge is minimum, the sea surface level considerably drops and also the export through the strait. All the forcing functions used to force the hydrodynamic model are described in extenso in Staneva and Stanev (1999). Since the model is forced by climatological monthly mean fields, the results are representative of a situation typical of the mean Black Sea's climatological state.

The role of atmospheric sources of nutrient appears to be marginal compared to river input (total atmospheric $\mathrm{NO}_{3}+\mathrm{NO}_{2}$ input estimated to be $13 \%$ of the Danube input,
Kubilay et al., 1995). Also, the vertical fluxes of all biogeochemical state variables are set to zero at the surface. The bottom boundary of the water column is assumed to be impermeable except for sedimenting substances. Also, when they reach the bottom, the detritus enrich the sediments compartment $\beta_{n}$. This flux is compensated by an upward flux of ammonium produced by benthic remineralization with a time scale of $\frac{1}{k_{\mathrm{sed}}}$ :

$$
\begin{aligned}
& \left(\tilde{\lambda}^{y} \frac{\partial \omega}{\partial z}\right)=-\left|w_{\omega}^{s}\right| \omega \\
& \left(\tilde{\lambda}^{y} \frac{\partial n_{1}}{\partial z}\right)=k_{\text {sed }} \beta_{n} .
\end{aligned}
$$

The input of nutrient and detritus by the rivers (i.e. the Danube, the Dnepr and the Dnestr) is computed from monthly mean values obtained in the literature (e.g. Cociasu et al., 1997). At the Bosphorus Strait, monthly mean vertical profiles of inorganic nutrients and detritus are imposed from the data of Polat and Tugrul (1995). With the water in- and out-fluxes computed in the model, these mean profiles give an annual total nitrogen export of $150000 \mathrm{t}$ and an annual input from the Mediterranean Sea of $100000 \mathrm{t}$. These values are in a rather good agreement with the estimations of Polat and Tugrul, (1995) made from their mean nutrient profiles and the mean water in- and out-fluxes taken in the literature (Ozsoy and Unluata, 1997) which give an output of $177000 \mathrm{t}$ and an output of $60000 \mathrm{t}$.

Acknowledgements. We would like to thank J. Staneva and E. Stanev for having prepared hydrodynamical data fields. The authors also thank N. Nezlin and A. Kostianoy for their help in the validation of model results and the reviewers for their constructive remarks that help in the improvment of the manuscript. This work was supported by the National Fund for Scientific Research, Belgium. The first author thanks the EU for her Marie-Curie fellowship. This is the Publication 3435 of the NIOO-KNAW Netherlands Institute of Ecology and the MARE contribution 048.

Edited by: J. Middelburg

\section{References}

Altman, E. and Kumish, N.: Interannual and seasonal variability of the Black Sea fresh water balance, Trudi Gos. Oceanogr. Inst., 145, 3-15, 1986.

Andersen, V. and Nival, P.: A pelagic ecosystem model simulating production and sedimentation of biogenic particles: role of salps and copepods, Mar. Ecol.-Pr., 44, 37-50, 1988.

Beckers, J. M.: Application of a 3D model to the Western Mediterranean, J. Mar. Syst., 1, 315-332, 1991.

Beckers, J. M., Grégoire, M., Nihoul, J., Stanev, E., Staneva, J., and Lancelot, C.: Hydrodynamical processes governing exchanges between the Danube, the North Western continental shelf and the Black Sea's basin, Est. Coast. S., 54, 3, 459-472, 2002. 
Billen, G. and Lancelot, C.: Modelling benthic nitrogen cycling in temperate coastal ecosystems, in Nitrogen Cycling in Coastal Marine Environments, edited by Blackburn, T. H. and Sorensen, J., John Wiley and Sons Ltd., New York, 341-378, 1988.

Brewer, P. and Murray, J.: Carbon, nitrogen and phosphorus in the Black Sea, Deep-Sea I, 20, 803-818, 1973.

Buesseler, K., Livingston, H., and Casso, S.: Mixing between oxic and anoxic waters of the Black Sea as traced by Chernobil cesium isotopes, Deep-Sea I, 38, Suppl. 2a, S725-S745, 1991.

Callender, E. and Hammond, D. E.: Nutrient exchange across the sediment-water interface in the Potomac river estuary, Est. Coast. S., 15, 395-413, 1982.

Cociasu, A., Diaconu, V., Popa, L., Buga, L., Nae, I., Doragan, L., and Malciu, V.: The nutrient stock of the Romanian shelf of the Black Sea during the last three decades, in "Sensitivity to change: Black Sea, Baltic Sea and North Sea", edited by Ozsoy, E. and Mikaelyan, A., NATO ASI Series 2: Environment, 27, 49-63, Kluwer Academic Publishers, Dordrecht, 1997.

Codispoti, L. A. and Christensen, J. P.: Nitrification, denitrification and nitrous oxide cycling in the eastern tropical South Pacific Ocean, Mar. Chem., 16, 277-300, 1985.

Cokacar, T. and Ozsoy, E.: Comparative analyses and modelling for regional ecosystems of the Black Sea, in "Ecosystem modelling as a management tool for the Black Sea", edited by Ivanov, L. and Oguz, T., NATO ASI Series 2: Environmental Security, 47, 323-358, Kluwer Academic Publishers, Dordrecht, 1998.

Deleersnijder, E. and Nihoul, J. C. J.: Turbulent fields associated with the general circulation in the Northern Bering Sea, in "Small Scale turbulence and mixing in the ocean", edited by Nihoul, J. C. J. and Jamart, B. M., 77-93, Elsevier, Amsterdam, 1988.

Delhez, E.: Reconnaissance of the general circulation of the North-Western European Continental Shelf by means of a threedimensional turbulent closure model, Earth. Sci. R., 41, 3-29, 1996.

Deuser, W. G.: Organic-carbon budget of the Black Sea, Deep-Sea I, 18, 995-1004, 1971.

Devol, A. H.: Direct measurement of nitrogen gas fluxes from continental shelf sediments, Nature, 349, 319-321, 1991.

Dippner, J. W.: A lagrangian model of phytoplankton growth dynamics for the Northern Adriatic Sea, Cont. Shelf, 13, 331-355, 1993.

Elderfield, H., Luedke, N., McCaffrey, R., and Bender, M.: Benthic flux studies in Narragansett Bay, Am. J. Sci., 281, 768-787, 1981.

Eppley, R.: New production: history, methods, problems, in "Productivity of the Ocean: Present and Past", edited by Berger, W. H., Smetacek, V. S., and Wefer, G., Dalhem Workshop report, 85-97, Wiley, Chichester, West Sussex, United Kingdom, 1989.

Finenko, Z.: Principles of the biological productivity of the Black Sea, Naukova Dumka (in Russian), 88-89, 1979.

Friedl, G., Friedrich, J., and Wehrli, B.: Nutrient fluxes in the lower Danube river, Danube delta and the coastal Black Sea, 2nd report of the E.U. INTAS project on the study of the nitrogen cycling in the oxic/anoxic environment of the Black Sea: Data analysis and numerical simulation, 144-159, Liège, 2001.

Friedrich, J., Dinkel, C., Friedl, G., Pimenov, N., Wijsman, J., Gomoiu, M.-T., Cociasu, A., Popa, L., and Wehrli, B.: Benthic nutrient cycling and diagenetic pathways in the north-western Black Sea, Est. Coast. S., 54, 3, 369-383, 2002.
Ginzburg, A. I., Kostianoy, A. G., and Sheremet, N. A.: On the use of satellite data in the study of seasonal and interannual variations of the Black Sea sea-surface temperature, Issledovanie Zemli iz kosmosa, 1, 51-61, 2001.

Globec report: Interdisciplinary model formulation and Parameterization, report on the second meeting of the international GLOBEC Numerical Modeling Working group, Nantes, July 1995, Globec International, Plymouth, UK, 1997.

Grégoire, M. and Lacroix, G.: Study of the Oxygen budget of the Black Sea waters using a 3D coupled hydrodynamicalbiogeochemical model, J. Mar. Syst., 31, 175-202, 2001.

Grégoire, M., Beckers, J. M., Nihoul, J. C. J., and Stanev, E.: Reconnaissance of the main Black Sea's ecohydrodynamics by means of a 3D interdisciplinary model, J. Mar. Syst., 16, 85-105, 1998.

Grégoire, M. and Lacroix, G.: Exchange Processes and Nitrogen Cycling on the shelf and continental slope of the Black Sea basin, Global Biog. 17, 2, 42-1-42-17, 2003.

Grégoire, M. and Friedrich, J.: Nitrogen Budget of the northwestern Black Sea shelf as inferred from modeling studies and in-situ benthic measurements, Mar. Ecol.-Pr., 270, 15-39, 2004.

Grégoire M., Nezlin, N., Kostianoy, A., and Soetaert K.: Modeling the nitrogen cycling and plankton productivity in an enclosed environment (the Black Sea) using a three-dimensional coupled hydrodynamical-ecosystem model, J. Geophys. Res.-O, 109, C5, 28p, 2004.

Honjo, S., Hay, B. J., Manganini, S., Asper, V. L., Degens, E. T., Ittekot, V., Kempe, S., Izdar, E., Konuk, Y. T., and Benli, H. A.: Seasonal cyclicity of lithogenic particle fluxes at a Southern Black Sea sediment trap station, in Particle flux in the ocean, edited by Degens, E. T., Izdar, E., and Honjo, S., 62, 1-18, Mitteilungen des Geologisch-Palaeontologischen Institutes, Universität Hamburg, 1987.

Humborg, C., Ittekot, V., Cociasu, A., and van Bodungen, B.: Effect of Danube river dam on Black Sea biogeochemistry and ecosystem structure, Nature, 386, 385-388, 1997.

Karl, D. and Knauer, G.: Microbial production and particle flux in the upper 350m Black Sea, Deep Sea-II, 38, Suppl. 2, S655S661, 1991.

Knauer, G. A.: Productivity and new production of the oceanic system, in Interactions of C, N, P and S Biogeochemical Cycles and Global Change, edited by Wollast, R., Mackenzie, F. T., and Chou, L., NATO ASI Series, 14, 211-231, Springer-Verlag, Berlin, 1993.

Konovalov, S. and Murray, J. W.: Variations in the chemistry of the Black Sea on a time scale of decades (1960-1995), J. Mar. Syst., 31, 217-243, 2001.

Konovalov, S., Ivanov, L. I., and Samodurov, A. S.: Oxygen, nitrogen and sulfide fluxes in the Black Sea, Mediterranean Marine Science, 1, 41-59, 2000.

Kubilay, N., Yemenicioglu, S., and Saydam, A.: Airborne material collections and their chemical composition over the Black Sea, Mar. Poll. B, 30, 475-483, 1995.

Lalli, C. M. and Parsons, T. R.: Biological Oceanography: An Introduction, Pergamon Press, Oxford, 301, 1993.

Lancelot, C., Staneva, J., Van Eeckhout, D., Beckers, J.-M., and Stanev, E.: Modelling the Danube-influenced north-western continental shelf of the Black Sea, Ecosystem response to changes in nutrient delivery by the Danube river after its damming in 1972, 
Est. Coast. S., 54, 3, 473-499, 2002.

Lebedeva, L. and Shushkina, E.: The model investigation of the Black Sea community changes caused by Mnemiopsis, Oceanology, 34, 79-87, 1994.

Lein, A. and Ivanov, M.: On the sulphur and carbon balances in the Black Sea, in Black Sea oceanography, edited by E. Izdar and J. Murray, NATO ASI Series C, 351, 307-318, Kluwer Academic Publishers, Dordrecht, 1991.

Madala, R. and Piacsek, S.: A semi-implicit numerical model for baroclinic oceans, J. Comput. Ph., 23, 167-178, 1977.

Mantoura, R. F. C., Law, C. S., Owens, N. J. P., Burkill, P. H., Woodward, E. M. S., Howland, R. J. M., and Llewellyn, C. A.: Nitrogen biogeochemical cycling in the north-western Indian Ocean, Deep Sea-I, 40, 651-671, 1993.

Martin, J. H., Knauer, G. A., Karl, D. M., and Broenkow, W. W.: VERTEX: carbon cycling in the northeast Pacific, Deep Sea-I, 34, 267-285, 1987.

McGillicuddy, D., Robinson, A., and McCarthy, J.: Coupled physical and biological modeling of the spring bloom in the North Atlantic (II): Three dimensional bloom and post-bloom effects, Deep Sea-I, 42, 8, 1389-1398, 1995.

Mikaelyan, A.: Winter bloom of the diatom Nitzchia delicatula in the open waters of the Black Sea, Mar. Ecol.-Pr., 129, 241-251, 1995.

Minas, H. J., Minas, M., Coste, B., Gostan, J., Nival, P., and Bonin, M. C.: Production de base et recyclage; une revue de base de le Méditerranée nord-occidentale, Oceanol. Act., 9, 155-162, 1988.

Mullin, M.: Some factors affecting the feeding of marine copepods of the genus Calanus, Limn. Ocean., 8, 239-250, 1963.

Muramoto, J. A., Honjo, S., Fry, B., Hay, B. R., Howarth, R. W., and Cisne, J. L.: Sulfur, iron and organic carbon fluxes in the Black Sea: sulfur isotopic evidence for origin of sulfur fluxes, Deep Sea-II, 38, Suppl. 2, S1,151-S1,187, 1991.

Murray, J., Codispoti, L., and Friederich, G.: Redox Environments: The suboxic zone in the Black Sea, in Aquatic chemistry: interfacial and interspecies processes, edited by Huang, C., O'Melia, C., and Morgan, J., 157-176, American Chemical Society, 1995.

Nezlin, N., Kostianoy, A., and Grégoire, M.: Patterns of seasonal and interannual changes of surface chlorophyll concentration in the Black Sea revealed from the remote sensed data, Remot. Sen. E., 69, 43-55, 1999.

Oguz, T., Ozsoy, E., Latif, A., Sur, H., and Unluata, U.: Modeling of hydrographically controlled exchange flow in the Bosphorus strait, J. Phys. Ocea., 20, 945-965, 1990.

Oguz, T., La Violette, P., and Unluata, U.: The upper layer circulation of the Black Sea : its variability as inferred from hydrographic and satellite observations, J. Geophys. Res.-O, 97, 12 569-12 684, 1992.

Oguz, T., Latun, V., Latif, M., Vladimirov, V., Sur, H., Markov, A., Ozsoy, E., Kotovschikov, B., Eremeev, V., and Unluata, U.: Circulation in the surface and Intermediate Layers of the Black Sea, Deep Sea-I, 40, 1597-1612, 1993.

Oguz, T., Ducklow, H. W., Malanotte-Rizzoli, P., Tugrul, S., Nezlin, N., and Unluata, U.: Simulation of annual plankton productivity cycle in the Black Sea by a one-dimensional physical-biological model, J. Geophys. Res.-O, 101, 16585-16599, 1996.

Oguz, T., Ducklow, H., Shushkina, E., Malanotte-Rizzoli, P., Tugrul, S., and Lebedeva, L.: Simulation of upper layer biochemi- cal structure in the Black Sea, in Ecosystem modelling as a management tool for the Black Sea, edited by Ivanov, L. and Oguz, T., NATO ASI Series 2: Environmental Security, 47, 257-300, Kluwer Academic Publishers, Dordrecht, 1998.

Oguz, T., Ducklow, H., Malanotte-Rizzoli, P., Murray, J., Shushkina, E., Vedernikov, V., and Unluata, U.: A physical-biochemical model of plankton productivity and nitrogen cycling in the Black Sea, Deep Sea-I, 46, 597-636, 1999.

Oguz, T., Ducklow, H., and Malanotte-Rizzoli, P.: Modeling distinct vertical biogeochemical structure of the Black Sea: Dynamical coupling of the oxic, suboxic, and anoxic layers, Global Biog., 14, 4, 1331-1352, 2000.

Özsoy, E. and Ü. Ünlüata: Oceanography of the Black Sea: A Review of Some Recent Results, Earth Sci. R., 42, 4, 231-272, 1997.

Ozsoy, E., Cokacar, T., Mikaelyan, A., and Besiktepe, S.: Model studies and analyses of ecosystem dynamics in the Black Sea, in "Ecosystem modelling as a management tool for the Black Sea", edited by Ivanov, L. and Oguz, T., NATO ASI Series 2: Environmental Security, 47, Kluwer Academic Publishers, Dordrecht, 1998.

Patankar, S.: Numerical heat transfer and fluid flow, Series in Computational Methods in Mechanical and thermal Sciences, McGraw-Hill, New-York, 197, 1980.

Patsch, J. and Radach, G.: Long-term simulation of the eutrophication of the North Sea: temporal development of nutrients, chlorophyll and primary production in comparison to observations, J. Sea Res., 38, 275-310, 1997.

Platt, T. and Jassby, A.: The relationship between photosynthesis and light for natural assemblages of coastal marine phytoplankton, J. Phycology, 12, 421-430, 1976.

Polat, C. and Tugrul, S.: Chemical exchange between the Mediterranean and the Black Sea via the Turkish Straits, Bulletin de l'Institut océanographique de Monaco, 37-56, 1995.

Rozanov, A. G.: Redox stratification in Black Sea waters, Oceanology, 35, 500-504, 1996.

Ryther, J. H.: Photosynthesis and fish production in the sea. The production of organic matter and its conversion to higher forms of life vary throughout the world ocean, Science, 166, 72-76, 1969.

Sarmiento, J., Slater, R., Fasham, M., Ducklow, H., Toggweiler, J., and Evans, G.: A seasonal 3D ecosystem model of nitrogen cycling in the North Atlantic euphotic zone, Global Biog., 7, 2, 415-450, 1993.

Saydam C., Tugrul, S., Basturk, O., and Oguz, T.: Identification of the oxic/anoxic interface by isopycnal surfaces in the Black Sea, Deep Sea-I, 40, 7, 1405-1412, 1993.

Soetaert, K., Herman, P., and Middelburg, J.: A model of early diagenetic processes from the shelf to abyssal depths, Geoch. Cos. A, 60, 6, 1019-1040, 1996.

Sorokin, Yu. I.: On the primary production and bacterial activities in the Black Sea, Journal du Conseil Permanent pour l'Exploration de la Mer, 29, 41-60, 1964.

Sorokin, Yu. I.: The Black Sea, in Estuaries and Enclosed Seas. Ecosystems of the World, edited by Ketchum, B. H., 253-292, Elsevier, New York, 1983.

Stanev, E. V.: On the mechanisms of the Black Sea circulation, Earth Sci. R., 28, 285-319, 1990.

Stanev, E. V. and Beckers, J. M.: Numerical simulations of seasonal 
and interannual variability of the Black Sea thermohaline circulation, J. Mar. Syst., 22, 241-267, 1999.

Staneva, J. V. and Stanev, E. V.: Oceanic Response to Atmospheric Forcing Derived from Different Climatic Data Sets. Intercomparison Study for the Black Sea, Oceanol. Act., 21, 393-417, 1999.

Staneva, J. V., Stanev, E. V., and Oguz, T.: The impact of atmospheric forcing and water column stratification on the yearly plankton cycle, in Ecosystem modelling as a management tool for the Black Sea, edited by L. Ivanov and T. Oguz, NATO ASI Series 2: Environmental Security, 47, 301-322, Kluwer Academic Publishers, Dordrecht, 1998.

Stelmakh, L. V., Yunev, O. A., Finenko, Z. Z., Vedernikov, V. I., Bologa, A. S., and Churilova, T. Yu.: Peculiarities of seasonal variability of primary production in the Black Sea, in Ecosystem modelling as a management tool for the Black Sea, edited by Ivanov, L. and Oguz, T., NATO ASI Series 2: Environmental Security, 47, 93-104, Kluwer Academic Publishers, Dordrecht, 1998.

Sur, H., Ozsoy, E., and Unluata, U.: Boundary current instabilities, shelf mixing and eutrophication processes in the Black Sea, Prog. Ocean, 33, 249-302, 1994.

Taguchi, K. and Nakata, K.: Analysis of water quality in Lake Hamana using a coupled physical and biochemical model, J. Mar. Syst., 16, 107-132, 1998.

Totterdell, I., Armstrong, R., Drange, H., Parslow, J., Powell, T., and Taylor, A.: Trophic resolution, in Towards a model of ocean biogeochemical processes, edited by G. Evans and M. Fasham, NATO ASI Series I: Global environmental change, 10, 71-92, Springer Verlag, 1993.

Tugrul, S., Basturk, O., Saydam, C., and Yilmaz, A.: Changes in the hydrochemistry of the Black Sea inferred from water density profiles, Nature, 359, 137-139, 1992.
Tusseau-Vuillemin, M. H., Mortier, L., and Herbaut, C.: Modeling nitrate fluxes in an open coastal environment (Gulf of Lions): Transport versus biogeochemical processes, J. Geophys. Res.-O, 103, 7693-7708, 1998.

Unluata, U., Oguz, T., Latif, M., and Ozsoy, E.: On the physical oceanography of the Turkish Straits, in The physical oceanography of Sea Straits, edited by L. J. Pratt, NATO ASI, 25-60, Kluwer Academic Publishers, Dordrecht, 1990.

Vedernikov, V. I. and Demidov, A. B.: Primary production and chlorophyll in the deep regions of the Black Sea, Oceanology, 33, 193-199, 1993.

Wijsman, J.: Early diagenetic processes in northwestern Black Sea sediments, $\mathrm{PhD}$ thesis, Netherlands Institute of Ecology, The Netherlands, 2001.

Wijsman, J., Herman, P., Gomoiu, M. T. : Spatial distribution in sediment characteristics and benthic activity on the northwestern Black Sea shelf, Mar. Ecol.-Pr., 181, 25-39, 1999.

Wollast, R.: The global coastal ocean. Processes and methods, in The Sea, edited by Brink, K. H. and Robinson, A. R., 10, $213-$ 252, John Wiley and Sons Ltd., New York, 1998.

Yakushev, E.: Mathematical Modelling of oxygen, nitrogen, sulphur and manganese cycling in the Black Sea, in Ecosystem modelling as a management tool for the Black Sea, edited by Ivanov, L. and Oguz, T., NATO ASI Series 2: Environmental Security, 47, 373-385, Kluwer Academic Publishers, Dordrecht, 1998.

Yakushev, E. and Neretin, L.: One-dimensional modelling of nitrogen and sulphur cycles in the aphotic zones of the Black Sea and Arabian Sea, Global Biog., 11, 3, 401-414, 1997.

Yanagi, T., Yamamoto, T., Koizumi, Y., Ikeda, T., Kamizono, M., and Tamori, H.: A numerical model of red tide formation, J. Mar. Syst., 6, 269-285, 1995. 